\title{
Density fractions versus size separates: does physical fractionation isolate functional soil compartments?
}

\author{
C. Moni ${ }^{1,3}$, D. Derrien ${ }^{2}$, P.-J. Hatton ${ }^{2}$, B. Zeller ${ }^{2}$, and M. Kleber ${ }^{1}$ \\ ${ }^{1}$ Department of Crop and Soil Science, Oregon State University, Corvallis, OR, USA \\ ${ }^{2}$ INRA-Nancy, Biogeochimie des Ecosystemes Forestiers, 54280 Champenoux, France \\ ${ }^{3}$ Norwegian Institute for Agricultural and Environmental Research, 1432 Ås, Norway
}

Correspondence to: C. Moni (christophe.moni@bioforsk.no)

Received: 11 June 2012 - Published in Biogeosciences Discuss.: 13 July 2012

Revised: 22 November 2012 - Accepted: 23 November 2012 - Published: 17 December 2012

\begin{abstract}
Physical fractionation is a widely used methodology to study soil organic matter (SOM) dynamics, but concerns have been raised that the available fractionation methods do not well describe functional SOM pools. In this study we explore whether physical fractionation techniques isolate soil compartments in a meaningful and functionally relevant way for the investigation of litter-derived nitrogen dynamics at the decadal timescale. We do so by performing aggregate density fractionation (ADF) and particle size-density fractionation (PSDF) on mineral soil samples from two European beech forests a decade after application of ${ }^{15} \mathrm{~N}$ labelled litter.

Both density and size-based fractionation methods suggested that litter-derived nitrogen became increasingly associated with the mineral phase as decomposition progressed, within aggregates and onto mineral surfaces. However, scientists investigating specific aspects of litter-derived nitrogen dynamics are pointed towards ADF when adsorption and aggregation processes are of interest, whereas PSDF is the superior tool to research the fate of particulate organic matter (POM).

Some methodological caveats were observed mainly for the PSDF procedure, the most important one being that fine fractions isolated after sonication can not be linked to any defined decomposition pathway or protective mechanism. This also implies that historical assumptions about the "adsorbed" state of carbon associated with fine fractions need to be reevaluated. Finally, this work demonstrates that establishing a comprehensive picture of whole soil OM dynamics requires a combination of both methodologies and we offer a suggestion for an efficient combination of the density and size-based approaches.
\end{abstract}

\section{Introduction}

Physical fractionation methods have been frequently employed in soil research because they can isolate such subsets of soil materials that are important to assess the accessibility of soil organic matter (SOM) and the bioavailability or sequestration of limiting nutriments such as nitrogen (Balesdent, 1996; Gregorich et al., 2006; von Lützow et al., 2007). There are conflicting views in the literature about the relevance of the fractions isolated by size and density fractionation, especially with regard to processes ruling sequestration of litter residues on the long term.

All physical fractionation protocols involve various degrees of soil dispersion, followed by density and/or size separation to isolate pools of SOM based on their size and degree of organo-mineral interaction (Torn et al., 2009). Moderate dispersion treatments include: various types of shaking with or without glass beads, mild sonication, slacking, disruption with a jet of water, blade mixing, and wet sieving (e.g. Billings et al., 2006; Huygens et al., 2005; Kong et al., 2005; Shang and Tiessen, 2000; Six et al., 2002a). Strong dispersion treatments include chemical dispersion with sodium hexametaphosphate and high-energy sonication treatments (e.g. Lehman et al., 2001; Sohi et al., 2001). Depending on the extent of force used, dispersion generates two types of products: individual particles and complex aggregates. These provide different kinds of information:

- Particle fractionations are based on the idea that equivalent soil particles are the seat of equivalent OM dynamic controlling processes. This type of procedure allows 
the study of adsorption and litter fragmentation mechanisms.

- Aggregate fractionation procedures are based on the assumption that soil structure is a major control on SOM turnover through physical protection. The emphasis of aggregate fractionations is on the isolation of ecologically meaningful subunits of the soil structure.

After dispersion has been achieved, soil components are separated either by size, density, or both. Size separation mostly relies on wet sieving for soil subunits coarser than $20 \mu \mathrm{m}$, and sedimentation for finer soil subunits. The sedimentation method is based on Stokes' law, but the conditions for its validity, which are a spherical shape of particles/aggregates and homogenous particle/aggregate density, are never realised in soil systems (Chenu and Plante, 2006). The consequence is an inherent yet unknown degree of experimental error, which effectively turns the sedimentation approach into some kind of density-size separation method, as opposed to a physically rigorous size separation.

Density separation is usually performed through floatation or swirling decantation procedures. Floatation can be performed on water to isolate intact plant remnants with a density $>1 \mathrm{~g} \mathrm{~cm}^{-3}$, or in dense liquids, such as colloidal silica ("Ludox"), NaI or Sodium Polytungstate (SPT) to separate aggregates or particles composed of minerals that vary in density. SPT-solutions are currently the most popular separation liquids because SPT is non-toxic and allows to create solutions as dense as $2.8 \mathrm{~g} \mathrm{~cm}^{-3}$. SPT is known to be a mild dispersant (Virto et al., 2008; Cerli et al., 2012), and to solubilise a certain proportion of $\mathrm{C}$ which may redistribute across fractions or become lost with the supernatant (Chenu and Plante, 2006; Crow et al., 2007; Six et al., 1999; Virto et al., 2008; Cerli et al., 2012). In general, floatation methods are limited by their inefficiency to properly separate soil elements that float from those that settle down slowly because of their small size or because of a density close to that of the separating liquid (Kaiser and Guggenberger, 2007).

In the following paragraphs, we briefly introduce and define the major types of fractionation procedures. A compilation is given in Fig. 1.

- Particle density fractionation (PDF) is based on the assumptions that (i) the association or the absence of associations with the mineral phase control OM dynamics (e.g. Rumpel et al., 2000; Swanston et al., 2002; Whalen et al., 2000), and that (ii) the mineralogy of the minerals within the size fractions is distinct and of variable effect on the stability of the adsorbed SOM. Recent examples include the study of mineral-specific associations with organic matter and mineral-specific bonding mechanisms (e.g. Basile-Doelsch et al., 2007, 2009). PDF is the best method available to separate POM from mineral-associated OM. Its usefulness is limited by the difficulty to fully disperse fine particles and to separate

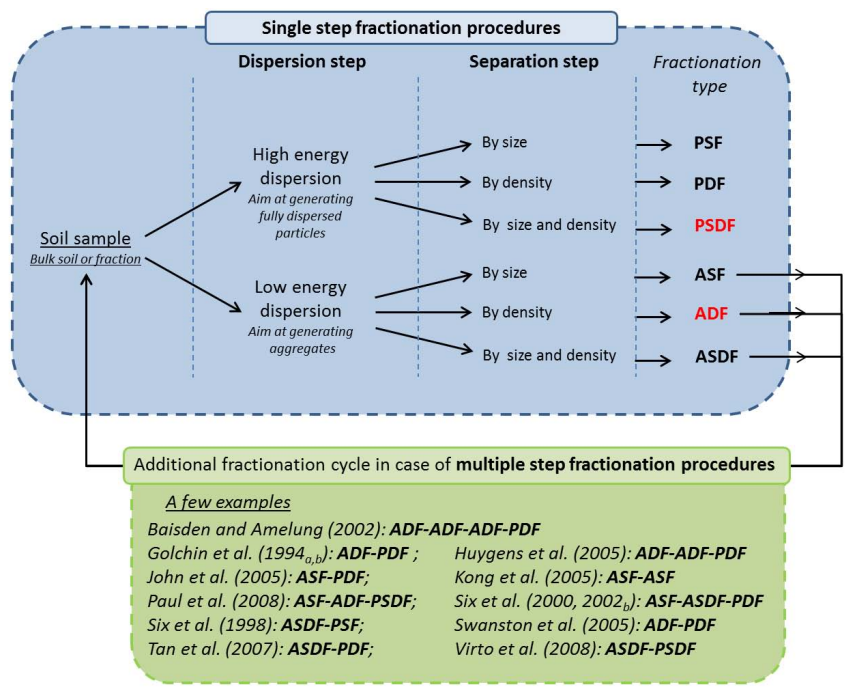

Fig. 1. Flow chart to illustrate methodological differences between soil fractionation procedures. PDF = Particle density fractionation; $\mathrm{PSF}=$ Particle size fractionation; $\mathrm{ADF}=$ Aggregate density fractionation; $\mathrm{ASF}=$ Aggregate size fractionation $\mathrm{PSDF}=$ Particle size density fractionation and ASDF = Aggregate size density fractionation. ADF and PSDF are highlighted in red because they were chosen for this study.

very fine particles of different mineralogy (Chenu and Plante, 2006; Kaiser and Guggenberger, 2007).

- Particle size fractionation (PSF) (e.g. Amelung et al., 1999; Jimenez et al., 2011; Rumpel et al., 2000; Sa et al., 2001; Schmidt et al., 1999b; Solomon et al., 2000, 2002) was based on the assumption that the state of decomposition of associated SOM should be a function of particle size as decay induces fragmentation. This procedure does not allow to segregate plant debris (free $\mathrm{OM}$ ) from more processed and protected mineral-bound OM.

- Particle size-density fractionation (PSDF) is a procedure where an additional density separation step is used to remove particulate organic matter (POM) of low density from coarse fractions generated by a prior size separation. It has been performed using both $\mathrm{H}_{2} \mathrm{O}$ as a separation liquid (e.g. Balesdent, 1996; Balesdent et al., 1991, 1998; Derrien et al., 2006) and flotation on denser liquids (e.g. Kapkiyai et al., 1999; Sohi et al., 2001). This method allows to separate POM according to decomposition stage. It is less useful for the study of mineral-bound $\mathrm{OM}$ as there is no robust relation between mineralogy and particle size.

- Aggregate density fractionation $(A D F)$ (e.g. Arnarson and Keil, 2001; Billings, 2006; Bock and Mayer, 2000; Castanha et al., 2008; Crow et al., 2007; Echeverria et al., 2004; Hatton et al., 2012; Sollins et al. 2006) was 
developed to separate true aggregate fractions of intermediate density from dispersed individual particles that could be either dense/mineral or light/organic. Considering that ADF procedures do not rely on strong ultrasonic dispersion, the contamination of the true aggregates fractions by low-density and/or very smallsized organo-mineral complexes should be fairly limited (Kaiser and Guggenberger, 2007). See Table 1 for a definition of true aggregate fractions.

- Aggregate size fractionation (ASF) (e.g. Bayer et al., 2000; Billings, 2006; Jimenez et al., 2011; John et al., 2005; Moni et al., 2010; Ranjard et al., 2000) is based on the assumption that OC acts as a sort of "glue" in aggregates and that aggregate size is directly related to the state of decomposition of the organic carbon. ASF fractionation can not isolate true aggregate fractions. Rather it generates a mixture of POM, fully dispersed particles, and aggregates, which renders a robust interpretation difficult.

- Aggregate size-density fractionation (ASDF) (e.g. Cayet and Lichtfouse, 2001; Lehmann et al., 2001; Magid et al., 2010; Nelson et al., 1994; Römkens et al., 1999; Shang and Tiessen, 2000) relies on the same ideas as the $A S F$ but a density separation is performed together with the size separation to ensure that only true aggregates are separated by size. Provided that the true aggregate fraction is properly isolated, the ASDF procedure, like the PSDF, is very useful to investigate the role of soil structure in SOM-dynamics.

The above mentioned fractionation procedures all involve a single dispersion step and are thus designated single step fractionation procedures. Multiple step fractionation procedures (Fig. 1) involve the successive redispersion/separation of aggregate fractions obtained from a single step fractionation procedure and were frequently used to investigate the internal architecture of soil aggregates (e.g. Baisden et al., 2002; Golchin et al., 1994a, b, 1995a, b; Huygens et al., 2005; John et al., 2005; Kong et al., 2005; Paul et al., 2008; Six et al., 1998, 2000; Swanston et al., 2005; Tan et al., 2007; Virto et al., 2008). Multiple step procedures are inspired by the aggregate hierarchy concept (Oades, 1984; Oades and Waters, 1991; Tisdall and Oades, 1982), which posits that large, fast cycling aggregates are made of small slow cycling aggregates and that this aggregate organisation controls SOM dynamics in soil. Multiple step fractionation procedures are the most informative fractionation procedures available to date, at the cost of being time consuming and susceptible to error propagation.

This study was undertaken to evaluate the specificity and relevance of the information provided by size and density fractionations. In response to conflicting views in the literature, we wanted to clarify whether physical fractions may allow the observer to identify (i) functional subunits of the soil fabric and (ii) the associated process of litter-derived nitrogen sequestration over a decade. Given access to a unique ${ }^{15} \mathrm{~N}$ labelling experiment, we were able to track the progress of the ${ }^{15} \mathrm{~N}$ label through physical fractions and to estimate the extent to which a given physical fraction might be involved in the retention of litter-derived $\mathrm{N}$, a decade after litterfall.

The fractionation procedures selected for this study include an aggregate density fractionation (ADF) protocol that has shown promise as a means to isolate ecologically meaningful aggregate structures (Hatton et al., 2012), while traditional particle size-density fractionation (PSDF) was selected because it can be considered as one of the most detailed and widely established fractionation procedures. The choice of protocols for this comparison was further governed by the intention to achieve a maximum of physical diversity among individual fractions (i.e. single mineral particles, particulate organic matter (POM), fine fractions, and aggregates) that would allow us to generalize results to other fractionation procedures not tested in this research. The fractions obtained were characterised by a suite of analytical techniques with emphasis on parameters that would be informative of the intensity of $\mathrm{N}$ turnover.

Our strategy to draw inference involved two steps. First, principle component analysis (PCA) was used to reduce the set of organic matter-related data (including $\mathrm{C}$ and $\mathrm{N}$ contents, $\mathrm{C} / \mathrm{N}$ ratio, $\delta^{13} \mathrm{C}$ ) to two independent variables or principal components (PC) that accounted for the majority of the data variability. The second step consisted of resolving the plane defined by the two principal components into contour maps of ${ }^{15} \mathrm{~N}$ label incorporation among physical fractions from both fractionation procedures. By doing this, the dynamics of litter-derived $\mathrm{N}$ transformation can be visualized as trajectories in the PCA plane.

\section{Materials and methods}

\subsection{Experimental design}

A detailed description of soil sites and sampling procedures was given by Hatton et al. (2012). Briefly, soils were collected from long-term field experiments located at Ebrach (Germany, $49^{\circ} 52^{\prime} \mathrm{N}, 10^{\circ} 27^{\prime} \mathrm{E}$ ) and Fougères (France, $48^{\circ} 23^{\prime} \mathrm{N}, 1^{\circ} 8^{\prime} \mathrm{W}$ ) (Table 2). Both sites represent managed beech forests (Fagus sylvatica L.). According to the FAO classification (IUSS Working Group WRB, 2006), Ebrach is an acidic dystric Cambisol with a sandy loam texture, while Fougères keyed out as an acidic glossalbic Cambisol with a silty loam texture. Humus type was Moder for both sites.

At both sites, the label was applied as a single pulse of ${ }^{15} \mathrm{~N}$ labeled beech litter enriched to a ${ }^{15} \mathrm{~N}$ concentration of 2.5 atom \% at Ebrach and 2.1 atom \% at Fougères. Labeling involved foliar application of urea to ten-year-old beech trees in another forest (Zeller et al., 1998). In February 1996 at 
Table 1. Definitions.

\begin{tabular}{ll}
\hline "True" aggregate fraction & $\begin{array}{l}\text { Fraction that contains only aggregates, opposed to non-fully dispersed fractions } \\
\text { including a mixture of aggregates, POM and fully dispersed mineral particles, } \\
\text { which are sometimes referred to as aggregate fractions. }\end{array}$ \\
\hline Composite fractions & $\begin{array}{l}\text { Soil fractions made of heterogeneous elements, aggregated or not. These het- } \\
\text { erogeneous elements can be fully dispersed mineral particles, POM, oxide con- } \\
\text { cretions, or black carbon. }\end{array}$ \\
\hline Functional Soil Compartment (FSC) & $\begin{array}{l}\text { Represents an extra level of organisation, representing groups of physical frac- } \\
\text { tions in which the majority of constitutive elements (i.e. particles or aggregates) } \\
\text { undergo the same combination of decomposition processes. }\end{array}$ \\
\hline
\end{tabular}

Ebrach and in February 2000 at Fougères, undecomposed litters were removed and replaced by the labeled beech leaves in an amount equal to the respective mean annual leaf litter input and covered with a $2-\mathrm{cm}$ mesh nylon net (Zeller et al., 2001).

Twelve years (November 2007) and eight years (January 2008) after tracer application, labeled and control soils were collected at Ebrach and Fougères, respectively. Only the first $2.5 \mathrm{~cm}$ of the A horizon were collected and investigated in this study as most of the litter-derived ${ }^{15} \mathrm{~N}$ was concentrated here (Hatton et al., 2012). Samples were taken in triplicate and sieved to pass $2 \mathrm{~mm}$. Observable roots were removed. Replicates were stored at $+4{ }^{\circ} \mathrm{C}$. Soil moisture was measured at $105^{\circ} \mathrm{C}$.

\subsection{Particle size-density fractionation (PSDF)}

We followed a method originally proposed by Balesdent et al. (1991) and sequentially isolated the following size fractions: > 2000, 2000-630, 630-200, 200-63, 63-20, 20-6, 6$2,2-0.2,0.2-0.035$, and $<0.035 \mu \mathrm{m}$ (see Fig. 2). Deionised water $(360 \mathrm{ml})$ was added to $\sim 50 \mathrm{~g}$ of air-dried bulk soil, and shaken overnight with 20 glass beads (diameter $=5 \mathrm{~mm}$ ) to break all aggregates $>63 \mu \mathrm{m}$ while preserving the POM (Balesdent et al., 1998). The fractions $>63 \mu \mathrm{m}$ were recovered by wet sieving, whereas the fraction $<63 \mu \mathrm{m}$ was sonified using conditions calibrated to obtain a clay-sized fraction equivalent in proportion to that achieved during standard particle size analyses (Balesdent et al., 1998; Schmidt et al., 1999a). The input of energy delivered by the ultrasonic probe to the soil suspension (soil mass $(\mathrm{g})$ to water volume (ml) ratio of $1: 10$ ) was fixed at $320 \mathrm{~J} \mathrm{ml}^{-1}$ delivered over a $20 \mathrm{~min}$ period of time. An ice bath was used to limit temperature increase and to avoid loss of cavitational efficiency during sonication (Roscoe et al., 2000). The 63-20 $\mu \mathrm{m}$ fraction was then recovered by wet sieving, whereas all fractions $<20 \mu \mathrm{m}$ were separated by sequential sedimentation performed either under normal gravity for fractions $>2 \mu \mathrm{m}$ or under increased gravity for fractions $<2 \mu \mathrm{m}$. Assuming an average particle density of $2.44 \mathrm{~g} \mathrm{~cm}^{-3}$, equivalent to particles with a processed-OM content of $100 \mathrm{mg} \mathrm{g}^{-1}$ (see Fig. 1, Chenu and Plante, 2006), sedimentation times were deter-

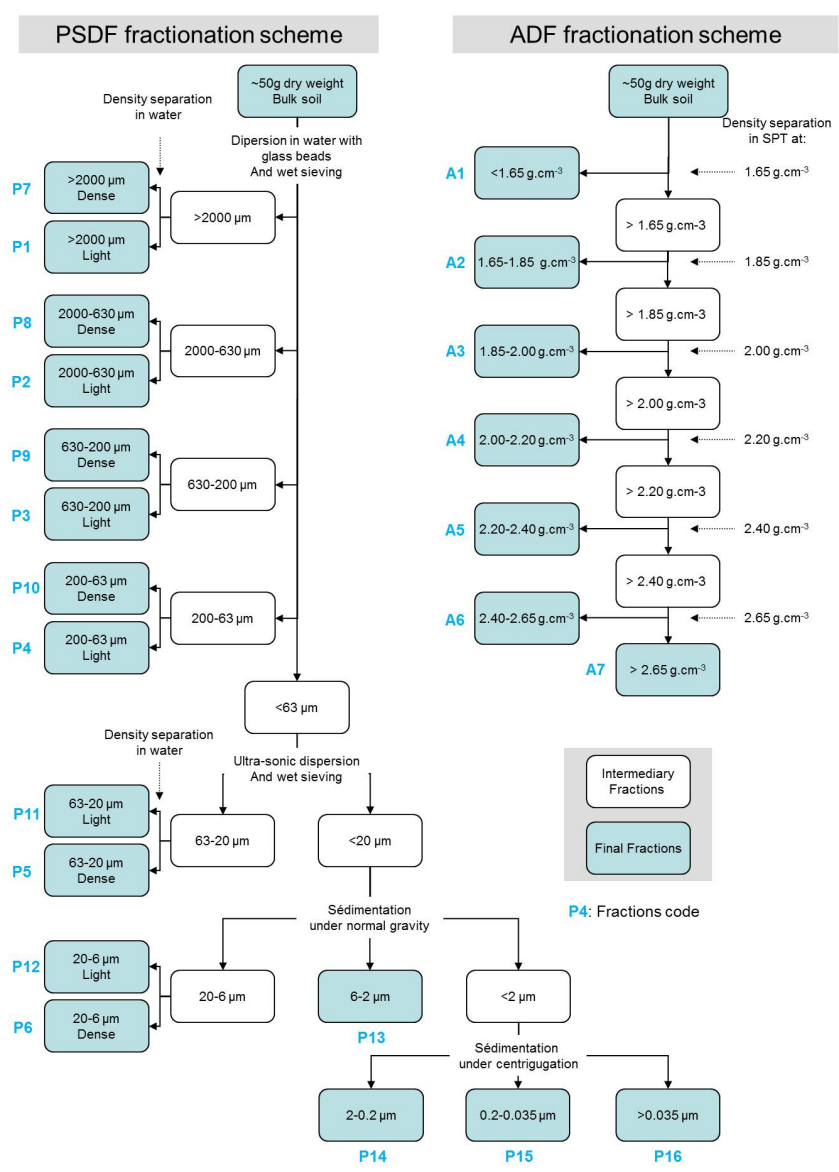

Fig. 2. PSDF and ADF fractionation schemes.

mined according to Stokes' law under normal gravity, and according to an adapted version under centrifugation (Poppe et al., 1988). Fractions coarser than $6 \mu \mathrm{m}$ were further separated using the swirling decantation method (e.g. Shang and Tiessen, 2000). Repeatedly, soil fractions immersed in water were gently swirled by hand in a beaker for a few seconds to achieve preferential resuspension of light organic particles as opposed to denser particles. Subsequently, the upper part of the supernatant containing POM was poured 
Table 2. Basic properties of the first $2.5 \mathrm{~cm}$ of the mineral soil.

\begin{tabular}{|c|c|c|c|c|c|c|c|c|c|}
\hline \multirow{2}{*}{$\begin{array}{c}\mathrm{C} \\
\left(\mathrm{mg} \mathrm{g}^{-1}\right)\end{array}$} & \multirow{2}{*}{$\begin{array}{c}\mathrm{N} \\
\left(\mathrm{mg} \mathrm{g}^{-1}\right)\end{array}$} & \multirow{2}{*}{$\mathrm{pH}_{\mathrm{H}_{2} \mathrm{O}}$} & \multirow{2}{*}{$\begin{array}{l}\mathrm{CEC}_{\mathrm{e}}^{*} \\
\left(\mathrm{mmol} \mathrm{kg}^{-1}\right)\end{array}$} & \multirow{2}{*}{$\begin{array}{l}\text { Base } \\
\text { saturation* } \\
(\%)\end{array}$} & \multirow{2}{*}{$\begin{array}{c}\text { Years after } \\
\text { the }{ }^{15} \mathrm{~N} \text { pulse } \\
(\mathrm{yr})\end{array}$} & \multirow{2}{*}{$\begin{array}{c}\text { Remaining } \\
{ }^{15} \mathrm{~N} \text { tracer } \\
(\%)\end{array}$} & \multicolumn{3}{|c|}{ Texture $(\%)$} \\
\hline & & & & & & & Sand & Silt & Clay \\
\hline \multicolumn{10}{|c|}{ Ebrach: dystric Cambisol } \\
\hline 45.9 & 2.0 & 3.9 & 87.8 & 34.5 & 12 & 11 & 76.2 & 19.0 & 4.8 \\
\hline \multicolumn{10}{|c|}{ Fougères: glossalbic Cambisol } \\
\hline 79.5 & 4.7 & 3.8 & 87 & 26 & 8 & 15 & 2.5 & 85.5 & 12.0 \\
\hline
\end{tabular}

Data from Hatton et al. $(2011)^{*}=$ values from depth $0-5 \mathrm{~cm}$.

away into another beaker. The procedure was repeated from 2 to 10 min until the coarse fraction isolated in the swirling beaker appeared free of dark, slowly sedimenting material. Coarse dense fractions were oven dried at $105^{\circ} \mathrm{C}$, whereas coarse light and fine fractions were freeze-dried.

\subsection{Aggregate density fractionation $(A D F)$}

Aggregate density fractionation was performed as described by Sollins et al. (2006) to isolate different soil fractions by flotation on sodium polytungstate solutions (SPT) of varying density. Seven density fractions were isolated: $<1.65 ; 1.65-$ $1.85 ; 1.85-2.0 ; 2.0-2.2 ; 2.2-2.4 ; 2.4-2.65$ and $>2.65 \mathrm{~g} \mathrm{~cm}^{-3}$ (see Fig. 2). Briefly, moist bulk soil samples were suspended in SPT solutions ( $1 / 3$ soil / SPT ratio) in $175 \mathrm{ml}$ polycarbonate centrifuge tubes and shaken initially for $2 \mathrm{~h}$ on a shaker table, before being centrifuged at a relative centrifugal force of $2560 \mathrm{~g}$ in a swinging bucket rotor for $10 \mathrm{~min}$. Density of the supernatant was checked using a $10 \mathrm{ml}$ volumetric flask combined with a precision balance. After adjusting density to target cutoffs $\left( \pm 0.01 \mathrm{~g} \mathrm{~cm}^{-3}\right)$, floaters and supernatant were aspirated down to the pellet using a vacuum system. SPT solution adjusted to the next higher density in the sequence was then added to the remaining soil pellet, shaken for $1 \mathrm{~h}$ and the same procedure repeated again. The SPT was removed from the isolated fractions using deionized water. The lightest fraction was filtered (Whatman GF/F $0.7 \mu \mathrm{m}$ particle retention) and subsequent fractions were rinsed several times in polycarbonate centrifuge bottles until a density $<1.01 \mathrm{~g} \mathrm{~cm}^{-3}$ was obtained. Once well cleaned, fractions were oven dried for 2 days at $+55^{\circ} \mathrm{C}$. Dried fractions were then weighed $( \pm 0.01 \mathrm{~g})$ and ground with a mortar and pestle to fine powder before further analyses. When moderate disaggregating treatment is applied, the specific densities of the embedded mineral grains, the mineral to organic ratio and the volume of voids within the aggregate determine the density of individual mineral-organic associations. This approach treats density isolates as functional soil subunits and therefore is thought to isolate associations that are more ecologically relevant than those obtained by traditional, more disruptive techniques. For more details see Hatton et al. (2012).

\subsection{Characterisation of physical fractions}

The seven aggregate fractions generated by the ADF procedure are designated A1-A7 in Figs. 3 and 4.

The PSDF procedure generates 16 fractions falling in three categories which we designate as follows:

(a) fractions $>6 \mu \mathrm{m}$ and with a mineral content that renders their density greater than that of water are labeled "coarse dense" (designated P7-P12 in Figs. 2, 3 and 4);

(b) fractions $>6 \mu \mathrm{m}$ whose mineral content is low enough to allow them to float on water are labeled "coarse light" (labeled P1-P6 in Figs. 2, 3 and 4);

(c) fractions $<6 \mu \mathrm{m}$ are labeled as "fine" (P13-P16 in Figs. 2, 3 and 4).

\subsubsection{Physical appearance}

All fractions were examined with a stereomicroscope. For PSDF, fractions were directly observed after drying, whereas fractions recovered by ADF were observed after dispersion in water. Aliquots were immersed in Petri dishes $(\varnothing: 4 \mathrm{~cm})$ filled with deionised water. Petri dishes were gently hand shaken to check for the presence of different density phases. Visual description was performed under a range of magnifications starting from $6 \times$ to $50 \times$. Samples were checked for: recognizable organic debris, black carbon, aggregates, and non-aggregated mineral particles (including oxides and concretions).

\subsubsection{C, $\mathrm{N}$ analyses}

Total C, total $\mathrm{N}, \delta^{15} \mathrm{~N}$ and $\delta^{13} \mathrm{C}$ were determined in triplicate using a 20-20 coupled continuous flow elemental analyserisotope ratio mass spectrometer (EA-IRMS; PDZ Europa Ltd., Crewe, Cheshire, England). The degree of microbial processing was determined using $\delta^{13} \mathrm{C}, \delta^{15} \mathrm{~N}$ and $\mathrm{C}: \mathrm{N}$ values as proxies (Baisden et al., 2002). In bulk soil and isolated fractions, the ${ }^{15} \mathrm{~N}$ tracer enrichment (excess ${ }^{15} \mathrm{~N} ; \mathrm{E}^{15} \mathrm{~N}(\%)$ ) was quantified as a proportion of total $\mathrm{N}$ as follows:

$\mathrm{E}^{15} \mathrm{~N}(\%)=\left(\mathrm{A}^{15} \mathrm{~N}(\%)_{\text {labelled_plot }}-\mathrm{A}^{15} \mathrm{~N}(\%)_{\text {control_plot }}\right)$ 


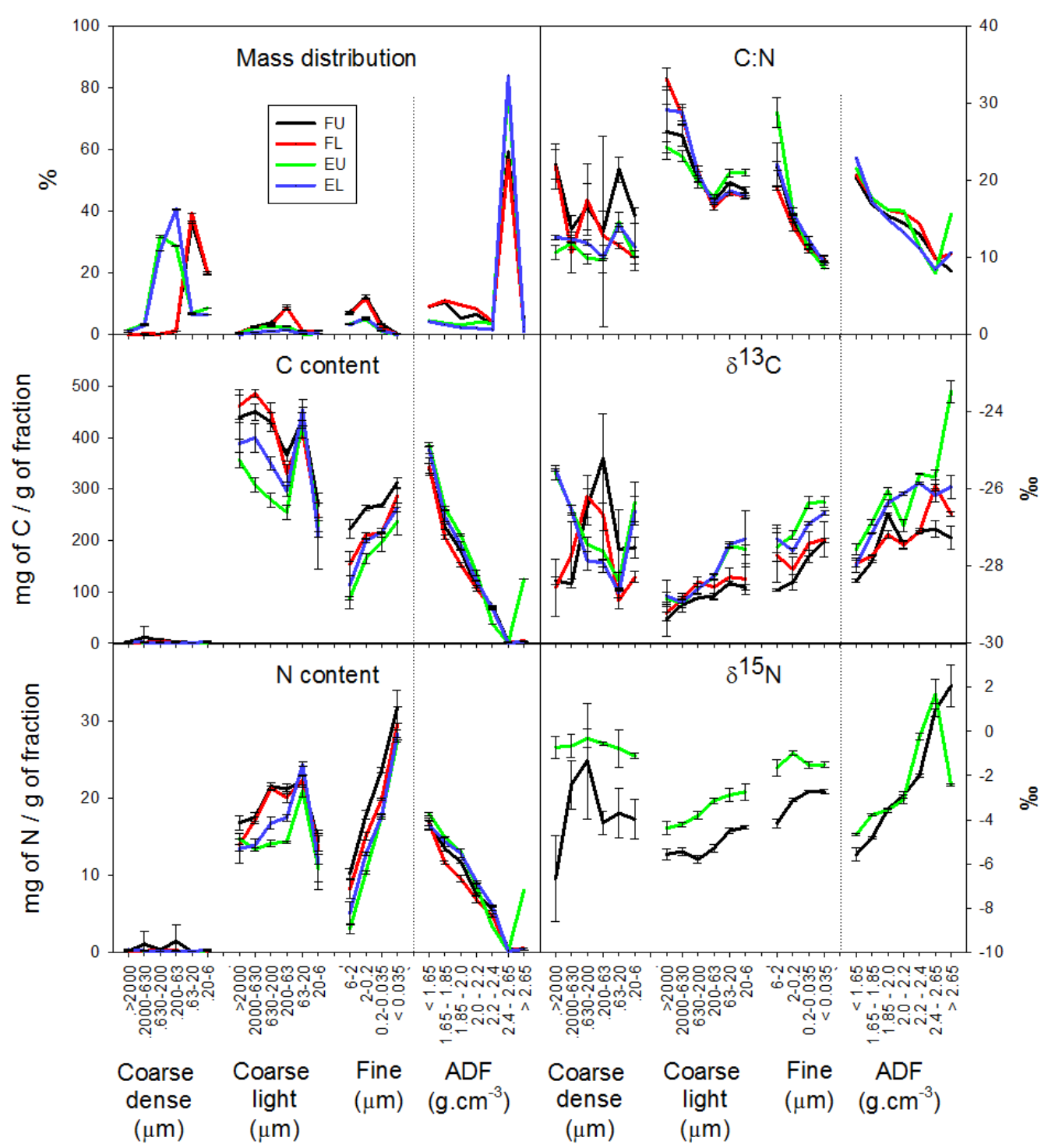

Fig. 3. Chemical characteristics of PSDF and ADF fractions isolated from Ebrach and Fougères labelled (El; FL) and unlabelled (EU; FU) soils. (Mass distribution, $\mathrm{C}$ and $\mathrm{N}$ contents, $\mathrm{C} / \mathrm{N}$ ratio, as well as, $\delta^{13} \mathrm{C}$ and $\delta^{15} \mathrm{~N}$ natural abundances.)

where $\mathrm{A}^{15} \mathrm{~N}(\%)_{\text {labelled_plot }}$ and $\mathrm{A}^{15} \mathrm{~N}(\%)_{\text {control_plot }}$ are the abundances of the ${ }^{15} \mathrm{~N}$ isotope, expressed in percent of total N, in labelled and reference plots. Since excess ${ }^{15} \mathrm{~N}$ does not include any dilution effect we also calculated the mass increase of ${ }^{15} \mathrm{~N}$ in isolated fractions, $G^{15} \mathrm{~N}$ :

$$
\begin{aligned}
G^{15} \mathrm{~N}\left(\frac{\mathrm{m} \mathrm{g}^{15} \mathrm{~N}}{100 \mathrm{~g} \text { soil }}\right) & =\mathrm{E}^{15} \mathrm{~N}(\%) \times \mathrm{N}\left(\frac{\mathrm{m} \mathrm{g}}{\mathrm{g} \text { fraction }}\right) \\
& \times \mathrm{Mf}\left(\frac{\mathrm{g} \text { fraction }}{100 \mathrm{~g} \text { soil }}\right),
\end{aligned}
$$

where $\mathrm{Mf}$ is the mass percentage and $\mathrm{N}$ the nitrogen content of the considered fraction. Total $\mathrm{C}$, total $\mathrm{N}, \delta^{15} \mathrm{~N}$ and $\delta^{13} \mathrm{C}$ data are presented as means of three replicates with their standard deviations.

\subsubsection{Principal component analysis}

Fractionation procedures were compared through standardized principal component analysis (PCA). The procedure reduces the overall variability in the data from the fractions by derivation of a small number of linear combinations of the original variables, called the principal components. The results of a PCA are usually discussed in terms of component scores and loadings (Shaw, 2003). Scores represent the coordinates of fractions in the new space defined by the principal components, while loadings represent the correlation between the principal components and the original variables. To perform the PCA, we combined the following original variables: $\mathrm{C}, \mathrm{N}, \mathrm{C} / \mathrm{N}$ ratio, $\mathrm{A}^{13} \mathrm{C}$ (i.e. abundance of the ${ }^{13} \mathrm{C}$ isotope in percent of total $\mathrm{C}$ ) measured on all the fractions 

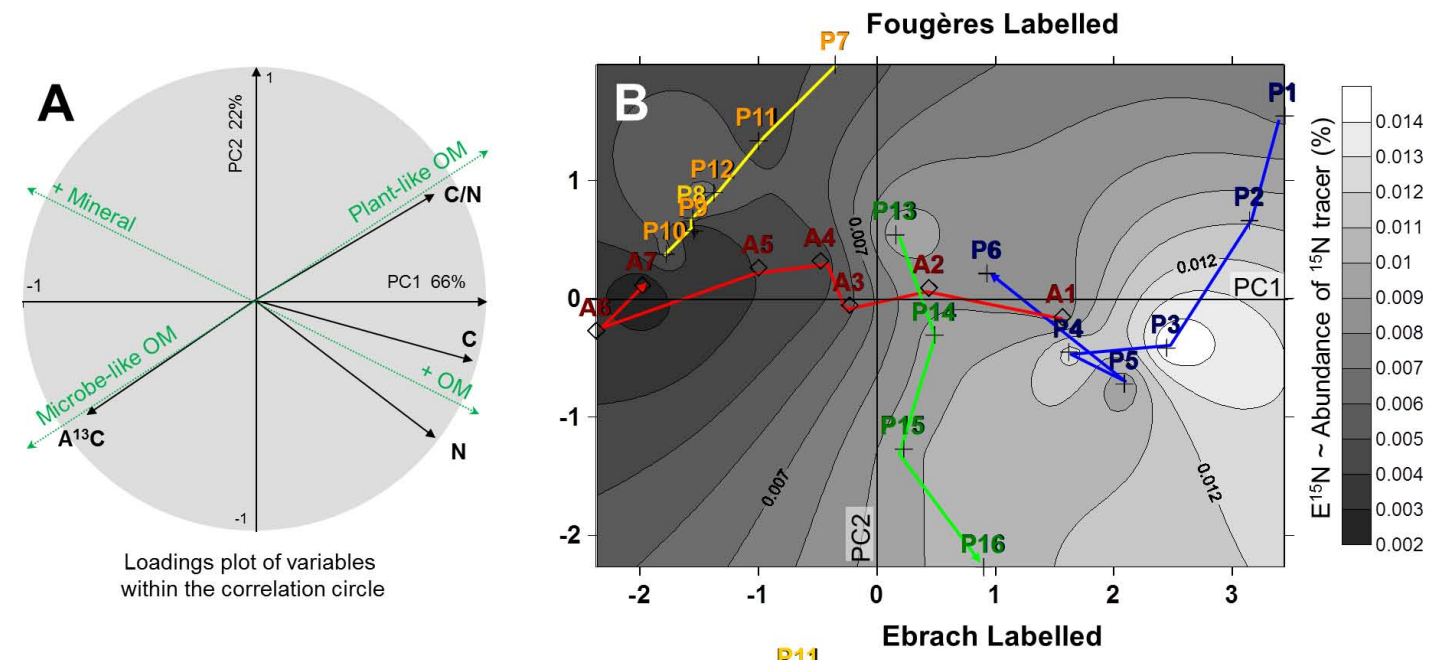

\begin{tabular}{lcc|}
\hline \multicolumn{3}{|c|}{+ PSDF } \\
$\begin{array}{l}\text { Fractions } \\
(\mu \mathrm{m})\end{array}$ & $\begin{array}{c}\text { Coarse } \\
\text { light }\end{array}$ & $\begin{array}{c}\text { Coarse } \\
\text { dense }\end{array}$ \\
$>2000$ & P1 & P7 \\
$2000-630$ & P2 & P8 \\
$630-200$ & P3 & P9 \\
$200-63$ & P4 & P10 \\
$63-20$ & P5 & P11 \\
$20-6$ & P6 & P12 \\
& & \\
$6-2$ & Fine & \\
$2-0.2$ & P13 & \\
$0.2-0.035$ & P14 & \\
$<0.035$ & P15 & \\
& P16 & \\
& &
\end{tabular}

\begin{tabular}{l|l|}
\hline \multicolumn{2}{|c|}{$\diamond \mathrm{ADF}$} \\
\hline $\begin{array}{l}\text { Fractions } \\
\left(\mathrm{g} . \mathrm{cm}^{3}\right)\end{array}$ \\
$<1.65$ & $\mathrm{~A} 1$ \\
$1.65-185$ & $\mathrm{~A} 2$ \\
$1.85-2.0$ & A3 \\
$2.0-2.2$ & A4 \\
$2.2-2.4$ & A5 \\
$2.4-2.65$ & A6 \\
$>2.65$ & A7 \\
& \\
&
\end{tabular}

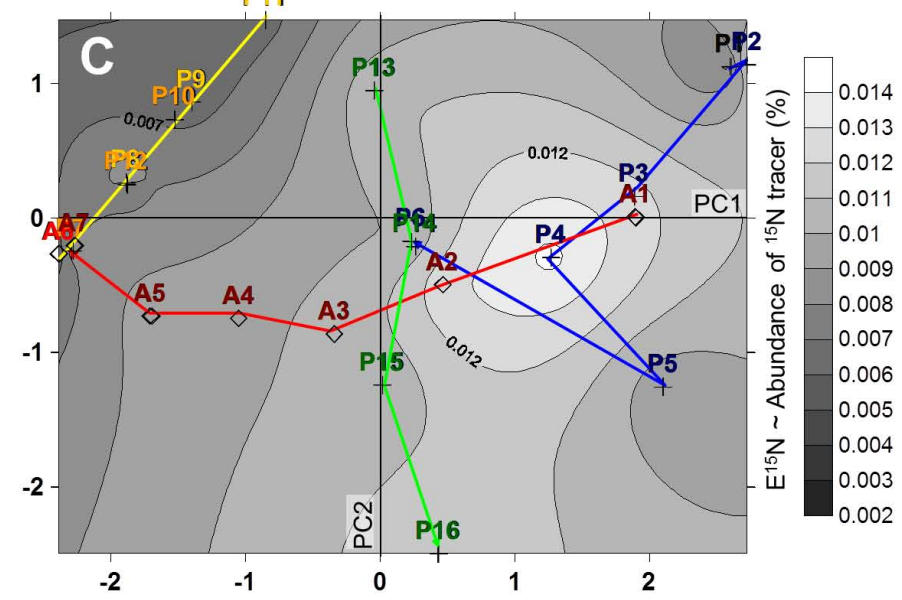

Blue trajectory: Particulate organic material with hyperbolic gradient from plant like over more microbial characteristics. High variation of the OM content after P4 observed for both soils is probably an artefact of the ultrasonic dispersion.

Yellow trajectory : Mineral material depleted in OM. Absence of trend within the trajectory due to decreasing accuracy of $\mathrm{C} / \mathrm{N}$ and $\mathrm{A}^{13} \mathrm{C}$ measurements at low $\mathrm{OM}$ content. High degree of similarity between soils

Green trajectory : clay (very fine silt) associated organic matter, increasing microbial character and increasing OM content with decreasing size, high degree of similarity between soils

Red trajectory : Mineral-organic matter mix, strong and unidirectional gradients for $\mathrm{C} / \mathrm{N}, \mathrm{C}, \mathrm{N}, \mathrm{OM}$ in both soils from purely organic material $A 1$ to purely mineral material $A 6$ and $A 7$, but decidedly more microbial character in the Ebrach soil

Fig. 4. Principal component analysis (PCA). PCA was performed for both sites independently on fractions isolated from labelled and unlabelled soil samples. Fractions were discriminated as a function of their $\mathrm{C}$ and $\mathrm{N}$ content, $\mathrm{C} / \mathrm{N}$ ratio and the abundance of ${ }^{13} \mathrm{C}, \mathrm{A}^{13} \mathrm{C}$. (A) Correlation circle between the new components and the original variables. (B) and (C) Score plots for labelled soil fractions only. Visualisation of ${ }^{15} \mathrm{~N}$ tracer abundance (see Equation $\mathrm{A}$ ) within fractions was performed by applying the relevant contour map as a background image. Interpolated contour maps were obtained by kriging using a default linear variogram (slope $=1$, nuggets effects $=0$ ) using the software "Surfer" v. 7.02). Fractions are grouped for similarity based on their level of affiliation with one of four clearly discernible trajectories (indicated by line style) within the PCA plane. A synthetized representation of the PCA results as well as its visual interpretation is given in Figs. 5 and 6.

isolated from Ebrach and Fougères, including both labelled and control treatments. Since we did not want to separate our fractions on the basis of the ${ }^{15} \mathrm{~N}$ labeling, $\mathrm{A}^{15} \mathrm{~N}(\%)$ was excluded from multivariate analyses. This way of representation constitutes a convenient way of assessing the level of similarity between fractions at a glance. Fractions whose positions are close together in the PCA plane share overall characteristics without being necessarily equivalent, i.e. an aggregate fraction can display the same carbon content as a fraction encompassing a mixture of fully dispersed mineral particles and POM.

Visualisation of the label incorporation within fractions was performed by applying a contour map representing the excess of ${ }^{15} \mathrm{~N}\left(\mathrm{E}^{15} \mathrm{~N}\right)$ in the plane, defined by the main PCs behind related scatter plots. Interpolated contour maps were obtained by kriging using a default linear variogram 
Table 3. Visual description of fractions.

\begin{tabular}{|c|c|c|c|c|c|c|c|c|c|c|}
\hline \multirow{3}{*}{ Fractions Names } & \multicolumn{5}{|c|}{ Ebrach: dystric Cambisol } & \multicolumn{5}{|c|}{ Fougères: glossalbic Cambisol } \\
\hline & \multicolumn{2}{|c|}{ Mineral phase } & \multicolumn{3}{|c|}{ Organic phase } & \multicolumn{2}{|c|}{ Mineral phase } & \multicolumn{3}{|c|}{ Organic phase } \\
\hline & $\begin{array}{l}\text { Quartz, } \\
\text { Feldspar }\end{array}$ & $\begin{array}{l}\text { Concretions/ } \\
\text { oxides }\end{array}$ & POM & Aggregates & $\begin{array}{l}\text { Black } \\
\text { carbon }\end{array}$ & $\begin{array}{l}\text { Quartz, } \\
\text { Feldspar }\end{array}$ & $\begin{array}{l}\text { Concretions/ } \\
\text { oxides }\end{array}$ & POM & Aggregates & $\begin{array}{l}\text { Black } \\
\text { carbon }\end{array}$ \\
\hline \multicolumn{11}{|c|}{ Particle Size Density Fractionation (PSDF) } \\
\hline \multicolumn{11}{|l|}{ Coarse dense } \\
\hline$>2000 \mu \mathrm{m}$ & & $100 \%$ & & & & $99 \%$ & +++ & & & + \\
\hline $2000-630 \mu \mathrm{m}$ & $50 \%$ & $50 \%$ & & & + & $99 \%$ & ++ & & & + \\
\hline $630-200 \mu \mathrm{m}$ & $99 \%$ & & + & & + & $99 \%$ & ++ & + & & + \\
\hline $200-63 \mu \mathrm{m}$ & $99 \%$ & & + & & + & $99 \%$ & + & + & & + \\
\hline $63-20 \mu m$ & $99 \%$ & & ++ & & + & $99 \%$ & & ++ & & + \\
\hline $20-6 \mu m$ & $99 \%$ & & ++ & & + & $99 \%$ & & ++ & & + \\
\hline \multicolumn{11}{|l|}{ Coarse light } \\
\hline$>2000 \mu \mathrm{m}$ & & & $99 \%$ & & + & & & $99 \%$ & & + \\
\hline $2000-630 \mu \mathrm{m}$ & & & $99 \%$ & & + & & & $99 \%$ & & + \\
\hline $630-200 \mu \mathrm{m}$ & + & & $99 \%$ & & + & + & & $99 \%$ & & + \\
\hline $200-63 \mu \mathrm{m}$ & + & & $99 \%$ & & + & + & & $99 \%$ & & + \\
\hline $63-20 \mu \mathrm{m}$ & ++ & & $99 \%$ & & + & ++ & & $99 \%$ & & + \\
\hline $20-6 \mu \mathrm{m}$ & ++ & & $99 \%$ & & + & ++ & & $99 \%$ & & + \\
\hline $\begin{array}{l}\text { Fine fractions } \\
<6 \mu \mathrm{m}\end{array}$ & \multicolumn{5}{|c|}{$\begin{array}{c}\text { Stereomicroscope insufficient resolution } \\
2 \text { distinct phases: a dark light organic and } \\
\text { a dense clear mineral }\end{array}$} & \multicolumn{5}{|c|}{$\begin{array}{c}\text { Stereomicroscope insufficient resolution } \\
2 \text { distinct phases: a dark light organic and } \\
\text { a dense clear mineral }\end{array}$} \\
\hline \multicolumn{11}{|c|}{ Aggregates Density Fractionation (ADF) } \\
\hline Density Fractions & & & & & & & & & & \\
\hline$<1.65 \mathrm{~g} \mathrm{~cm}^{-3}$ & + & & $99 \%$ & & + & + & & $99 \%$ & & + \\
\hline $1.65-1.85 \mathrm{~g} \mathrm{~cm}^{-3}$ & $10 \%$ & & +++ & $89 \%$ & + & $10 \%$ & & +++ & $89 \%$ & + \\
\hline $1.85-2.0 \mathrm{~g} \mathrm{~cm}^{-3}$ & $16 \%$ & & ++ & $83 \%$ & + & $16 \%$ & & ++ & $83 \%$ & + \\
\hline $2.0-2.2 \mathrm{~g} \mathrm{~cm}^{-3}$ & $26 \%$ & & + & $73 \%$ & + & $21 \%$ & & + & $78 \%$ & + \\
\hline $2.2-2.4 \mathrm{~g} \mathrm{~cm}^{-3}$ & $40 \%$ & & + & $59 \%$ & + & $35 \%$ & & + & $64 \%$ & + \\
\hline $2.4-2.65 \mathrm{~g} \mathrm{~cm}^{-3}$ & $99 \%$ & + & + & & & $99 \%$ & + & + & & \\
\hline$>2.65 \mathrm{~g} \mathrm{~cm}^{-3}$ & $80 \%$ & $20 \%$ & + & & & $80 \%$ & $20 \%$ & + & & \\
\hline
\end{tabular}

,,++++++ The fraction element is present as trace of increasing importance.

Fractions susceptible to be composite in term of OM.

Fractions composite* in term of OM.

( lope $=1$, nugget effects $=0$ ) using the software "Surfer", version 7.02. Here the goal was to provide an easy way to visualize a three dimensional data set.

\section{Results}

\subsection{Recoveries}

Mass losses in the course of the fractionation process were characterised by calculating mass budgets as well as $\mathrm{C}$ and $\mathrm{N}$ recovery rates. For both fractionation procedures mass losses never exceeded $2 \%$. Carbon and nitrogen recovery rates averaged $91.4 \pm 2.6 \%$ for ADF and $91.7 \pm 7.2 \%$ for PSDF and were similar to recovery values presented by other studies (Balabane and Plante, 2004; Balesdent et al., 1998; Schmidt et al., 2000; Schmidt and Kögel-Knabner, 2002; Schöning and Kögel-Knabner, 2006).

\subsection{Physical appearance of isolated fractions}

Microscopic observations of separates from Fougères and Ebrach are summarized in Table 3.

For ADF, the fraction $<1.65 \mathrm{~g} \mathrm{~cm}^{-3}$ was composed of free plant debris with minor encrustations of mineral grains. Fractions from 1.65 to $2.4 \mathrm{~g} \mathrm{~cm}^{-3}$ mostly consisted of aggregates whose content of non-aggregated mineral particles (determined after mild grinding and resuspension in water) increased with increasing density, from $10 \%$ to $60 \%$ of observed items.

Traces of charcoal (i.e. about $3 \%$ of items) were identified in every fraction below a density of $2.4 \mathrm{~g} \mathrm{~cm}^{-3}$. Fractions $>2.4 \mathrm{~g} \mathrm{~cm}^{-3}$ were mostly composed of non-aggregated mineral particles. Brown to red colored oxides and concretions were nearly exclusively observed in fractions $>2.65 \mathrm{~g} \mathrm{~cm}^{-3}$ and accounted for about $10 \%$ of the material there. 
For the PSDF, coarse dense fractions were almost exclusively composed of non-aggregated mineral particles, whereas coarse light fractions were almost exclusively composed of POM. The purity of these mineral and organic fractions slightly decreased with decreasing particle size, which illustrates that it became increasingly difficult to separate organic and mineral phases by density in water as particle size approached colloidal dimensions. Oxide concretions were observed in varying proportions in coarse dense fractions. Representing in mass up to $<1 \%$ and nearly $100 \%$ of the $>2000 \mu \mathrm{m}$ fractions at Fougère and Ebrach, respectively, their abundance decreased quickly with decreasing fraction size. A few particles of charcoal were identified in all coarse fractions (i.e. $>6 \mu \mathrm{m}$ ). Visual description of fine fractions was beyond the resolution of the stereomicroscope, yet it was still possible to see that the fine fractions were composed of two phases, a black one and white one with black fractions likely corresponding to low density materials and white ones to minerals.

\subsection{Basic characteristics of fractions}

For both fractionation procedures, fractions isolated from labeled and control soils had comparable $\mathrm{C}$ and $\mathrm{N}$ concentrations and $\mathrm{C} / \mathrm{N}$ ratio and similar $\delta^{13} \mathrm{C}$ values (Fig. 3).

Dry mass peaked in fraction $2.4-2.65 \mathrm{~g} \mathrm{~cm}^{-3}$ recovered from ADF with about $58 \%$ of total soil mass in this fraction at Fougères and $83 \%$ at Ebrach. These values were equivalent to the mass percentage of the coarse dense fractions isolated by PSDF in both soils. Mass proportions in other fractions isolated by ADF or PSDF ranged from 1 and $10 \%$ of dry weight. Soil mass distributions among fractions were similar between labeled and control soils (Fig. 3).

For both sites, $\mathrm{C}$ and $\mathrm{N}$ content of ADF fractions dropped by an order of magnitude from the lightest fraction to the two densest fractions. Some PSDF fractions exhibited some similarities with ADF fractions. Coarse dense fractions were as depleted in $\mathrm{C}$ and $\mathrm{N}$ as the $\mathrm{ADF}$ fractions that were denser than $2.4 \mathrm{~g} \mathrm{~cm}^{-3}$. Coarse light fractions had on average the same $\mathrm{C}$ and $\mathrm{N}$ concentrations as the lightest ADF fractions. Their $\mathrm{C}$ content slightly decreased with decreasing particle size with the exception of the $63-20 \mu \mathrm{m}$ fractions that reached a local maximum, while their $\mathrm{N}$ contents slightly peaked in the $63-20 \mu \mathrm{m}$ fractions. Within fine fractions, C and $\mathrm{N}$ increased with decreasing particle size.

$\mathrm{C} / \mathrm{N}$ ratios and natural abundance values of ${ }^{13} \mathrm{C}$ and ${ }^{15} \mathrm{~N}$ were used as indicators of microbial processing (Baisden et al., 2002). Within ADF fractions, $\mathrm{C} / \mathrm{N}$ ratios decreased and natural abundance of ${ }^{13} \mathrm{C}$ and ${ }^{15} \mathrm{~N}$ increased with increasing density from plant-like to microbe-like values (in Fig. 3; C:N ratios from $21 \pm 1$ to $11 \pm 3 ; \delta^{13} \mathrm{C}$ from $-28.0 \pm 0.3 \%$ to $-25.8 \pm 1.7 \%$ and natural $\delta^{15} \mathrm{~N}$ from $-3.4 \pm 0.6 \%$ o to $-0.1 \pm 3.2 \%$ o). Within the organic rich fractions generated by PSDF, i.e. coarse light and fine fractions, the same trend was observed with decreasing par- ticle size, $\left(\mathrm{C} / \mathrm{N}\right.$ ratios from $28 \pm 4$ to $9.4 \pm 4, \delta^{13} \mathrm{C}$ from $-29.1 \pm 0.3 \%$ to $-26.9 \pm 0.5 \%$ and natural $\delta^{15} \mathrm{~N}$ from $-3.3 \pm 0.8 \%$ o to $-1.4 \pm 0.9 \%$ o). In the coarse dense fractions generated by PSDF, no clear trend could be observed when size decreased: $\mathrm{C} / \mathrm{N}$ ratios ranged between 9.5 and 22, $\delta^{13} \mathrm{C}$ between $-29 \%$ and $-25 \%$, and natural $\delta^{15} \mathrm{~N}$ between $-7 \%$ and $0 \%$.

\subsection{Principal component analysis}

\subsubsection{Gradients within the PCA plane}

The two first principal components (PC) accounted for $88 \%$ of the total variance in the samples (Fig. 4 and Table 4, PC1 $66 \%, \mathrm{PC} 2: 22 \%$ ). With respect to component loadings (Table 4), two gradients set at $\sim 45^{\circ}$ from the PC1 and PC2 were identified (Fig. 4a). The first gradient was characterised by a decreasing $\mathrm{C} / \mathrm{N}$ ratio and increasing $\delta^{13} \mathrm{C}$, and represented the degree of $\mathrm{OM}$ microbial processing going from plant-like towards microbe-like characteristics. The second gradient followed increasing levels of $\mathrm{C}$ and $\mathrm{N}$ content and corresponded to the gradient of OM content within fractions.

\subsubsection{Plot of the isolated fractions in the PCA plane}

Coordinates of the isolated fractions in the plane defined by the two first components PC1 and PC2 were similar for both control and the label treatments. Therefore only fractions isolated from labeled plots are displayed in Fig. 4 (Fougères on panel B and Ebrach on panel C). A schematic interpretation of fraction distribution in the PCA plane is given in Fig. 5a.

In the PCA plane, fractions are separated along the two previously identified gradients according to their OM characteristics. Their geometric arrangement can be interpreted as indicating their proximity to either a plant- or microbelike state of $\mathrm{OM}$ and between an organic-depleted and a more organic-rich state. These four different states can be represented as the four sides of a parallelogram delimiting a space where all possible OM combinations may be observed (Fig. 5a). Consequently, fractions located within this space are characterized by intermediary carbon content and must be interpreted as composite fractions (defined as fractions neither purely organic nor purely mineral and made of heterogeneous elements that may be aggregated or not, see Table 1).

\section{$3.5 \quad{ }^{15} \mathrm{~N}$ tracer distribution in soil fractions a decade after litter application}

The ${ }^{15} \mathrm{~N}$ tracer was applied as a pulse of labelled litter on the top of the forest humus layer. Its release into the first centimetres of mineral soil took several years as shown by Zeller and Dambrine (2011). After a decade, ${ }^{15} \mathrm{~N}$ tracer peaked in the middle of the size ranges of both coarse light and fine fractions isolated by PSDF as well as in the two lightest ADF fractions (Fig. 6), revealing that these fractions acted 
Table 4. Eigenvalues and percentage of explained variance for the fraction datasets on OM quality.

\begin{tabular}{lrr}
\hline & PC1 & PC2 \\
\cline { 2 - 3 } Eigenvalues & 2.645 & 0.893 \\
Variance (\%) & 66.13 & 22.32
\end{tabular}

Correlation coefficients (loading) between the original reduced data and the two first components

\begin{tabular}{lrr}
\hline & PC1 & PC2 \\
\cline { 2 - 3 } $\mathrm{C}$ & 0.948 & -0.265 \\
$\mathrm{~N}$ & 0.787 & -0.599 \\
$\mathrm{C} / \mathrm{N}$ ratio & 0.770 & 0.465 \\
$\mathrm{~A}^{13} \mathrm{C}$ & -0.731 & -0.497 \\
\hline
\end{tabular}

PC: principal component.

A) Trend observed in this study
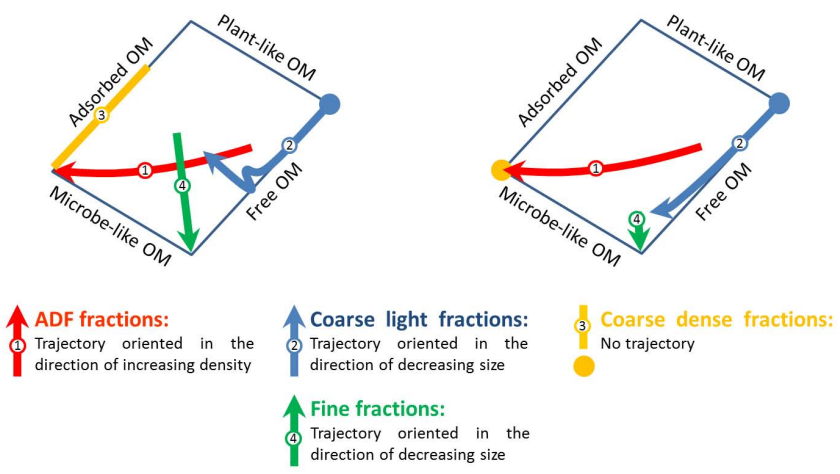

Fig. 5. Schematic representation of (A) the PCA results and (B) the change that could be expected in the PCA plane after application of the improved PSDF (Fig. 6) Fractionation procedure.

as recipient of litter residues at the decadal timescale. The transfer of ${ }^{15} \mathrm{~N}$ tracer in the coarse dense fractions isolated by PSDF was close to zero. In ADF fractions, ${ }^{15} \mathrm{~N}$ transfers steadily decreased with increasing density and were close to zero in the densest fraction.

Similar patterns were observed when expressing the amount of ${ }^{15} \mathrm{~N}$ as a proportion of the total $\mathrm{N}$ of the fraction $\left({ }^{15} \mathrm{~N}\right.$ Excess (\%) unit - Fig. 4). This latter unit provides useful information regarding $\mathrm{N}$ incorporation into the various fractions.

\section{Discussion}

\subsection{Process dynamics as inferred from the combination of fractionation procedures}

The numerous trajectories and trends revealed by the principal component analysis are described in Fig. 7

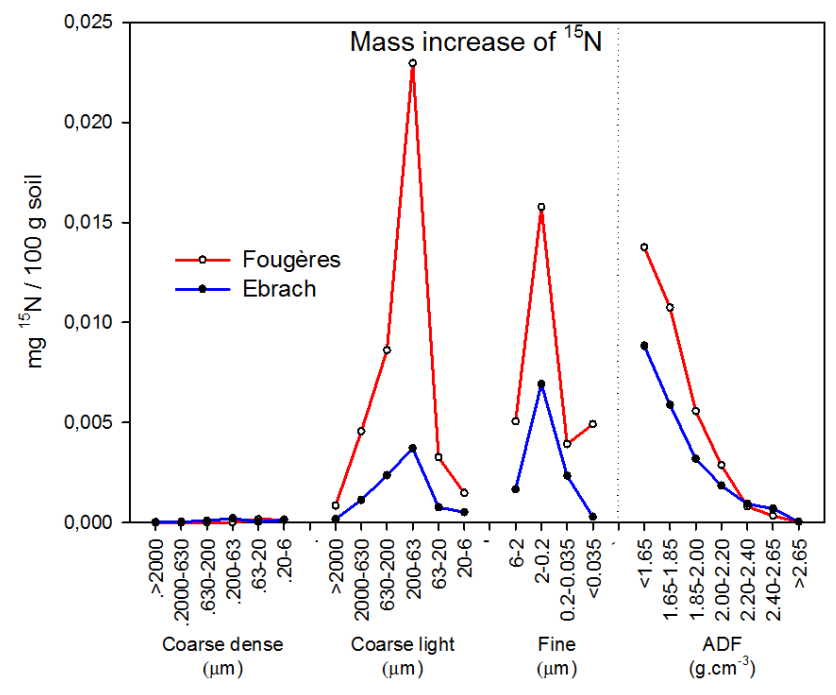

Fig. 6. Gain of ${ }^{15} \mathrm{~N}$ mass within fractions isolated by PSDF and ADF from Ebrach and Fougères soils.

- Fractions isolated from the ADF lined up along PC1 and eventually crossed the composite domain (see Figs. 4 and 5a) moving from the pole of unaltered fresh OM to the pole of adsorbed microbial-derived OM. This indicated that with increasing density, the level of microbial processing increased and the OM content decreased, and confirms the aggregated nature of mid-density fractions (Fig. 5).

- Fractions isolated from the PSDF followed a fundamentally different pattern and showed discrimination according to both principal components. Figs. 3 and 4 illustrate that the three groups of PSDF fractions (i.e. coarse dense, coarse light and fine fractions) were well separated.

- Coarse light fractions (upper right hand corner, Figs. 4 and 5a) were characterised by high positive scores on PC1 and PC2 that decreased with decreasing fraction size. Fractions $>63 \mu \mathrm{m}(\mathrm{P} 1, \mathrm{P} 2, \mathrm{P} 3$ and $\mathrm{P} 4)$ are on the gradient of increasing degree of OM microbial processing when they get finer. The application of ultrasonic dispersion to particles less than $63 \mu \mathrm{m}$ induced a sudden jump in OM content from P4 to P5 (see also Fig. 7 step 4). This process may have removed mineral matter loosely attached to organic particles $(63-20 \mu \mathrm{m})$, or may have redistributed OM from finer fractions, although several authors demonstrated ultrasonic dispersion has minor effects on OM redistribution within fine fractions (Morra et al., 1991; Oorts et al., 2005; Schmidt et al., 1999a; Yang et al., 2009). The next finer coarse light fractions (20-6 $\mu \mathrm{m}, \mathrm{P} 6)$ show less OM and more mineral matter. This increase of mineral matter from P5 to P6 was also evident from visual observation and is likely to result from an imperfect separation of organic 


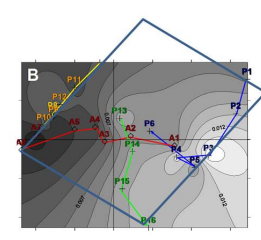

Fractions reside within a parallellogram defined by the
two gradients (I) and (II):

Positions within the parallelogram characterize as much the recovered fractions as the fractionation methods

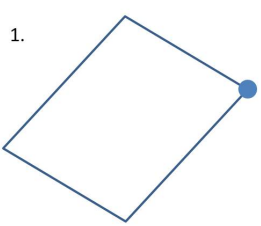

Blue dot: OM enters the soil as fresh plant material

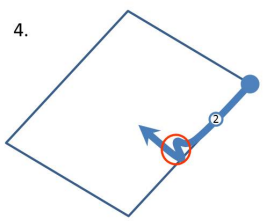

Ultrasonic dispersion generates "noise" in the density pattern

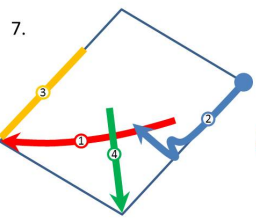

With progressing decomposition, OM fragments agregates of increasing density
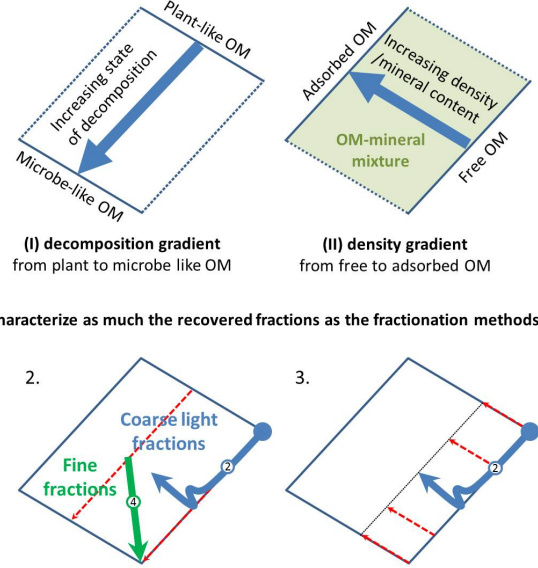

With increasing decomposition (dectreassing particlele size), OM
aquires a microbial signature

Density increases with decreasing isolation in water declines
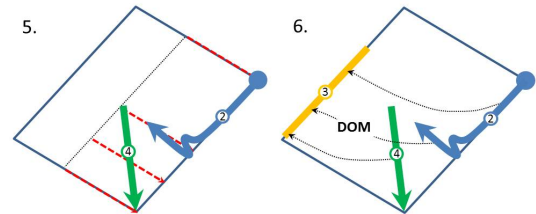

For Fine fractions, decreasing density with decreasing particle size is due to

DoM generated during a bias in the decantation methods onto mineral surfaces

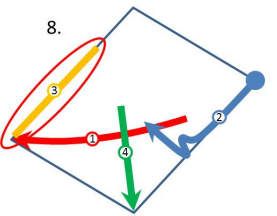

Organics adsorbed to ADF have a strong microbial may be due to dense black carbon particles whose exclusion is impossible in water
(I) decomposition gradient from plant to microbe like $\mathrm{OM}$ decomposition may adso

Fig. 7. Interpretative schemes of the PCA analysis presented in Fig. 4. Meanings of arrows are describes in Fig. 5. The green zone in the upper right scheme represents a zone where fractions must be composite (i.e. composed of elements that can be both aggregated and particulate).

matter from mineral particles during suspension in water (see also Fig. 7 step 3). In theory, had the dispersion and the separation of organic and mineral phases been ideal, coarse light fractions should have been restricted to the pole of pure $\mathrm{OM}$ and evolved from a plant like to a more microbe-like signature without entering into the composite domain of the PCA-plane.

- Coarse dense fractions (upper left hand corner, Figs. 4 and 5a) were characterised by high negative scores on $\mathrm{PC} 1$ and high positive scores on PC2. They were almost exclusively composed of non-aggregated mineral particles and had very low OM content. Coarse dense fractions were aligned parallel to the plant-microbe gradient at the adsorbed OM pole (Figs. 4 and 5a) and dif- fered mainly from each other by the extent to which the adsorbed $\mathrm{OM}$ had undergone microbial processing. However, decreasing particle size was not equivocally related to increasing degree of microbial alteration. This could in theory result from a lack of analytical sensitivity at low OM contents, but visual observations also suggested that some black carbon particles may have interfered with the detection of consistent change related to decreasing particle size. There have been reports of high density for black carbon particles (up to $2.4 \mathrm{~g} \mathrm{~cm}^{-3} \mathrm{ac}-$ cording to Glaser et al., 2000), which would make it impossible to segregate dense black carbon from mineral matter of similar density. Moreover, the imperfection of the density separation in water might be responsible for a contamination of the mineral phase by organic materials, negligible in terms of overall mass but significant in terms of OM content (see also Fig. 7 step 8).

- Fine fractions (Aligned with PC2 in the centre of Figs. 4 and 5a) were parallel with the PC2 axis and were characterised by PC2 scores that decreased with decreasing size of particles, indicating that OM content and the level of microbial processing increased with decreasing particle size (from P13 going to P16). The fact that fine fractions are located in the composite domain (see also Fig. 7 upper part) confirms that they combine all small scale organic or mineral debris that are generated by the ultra-sonic dispersion, and suggest that the statistical analysis used here might be suitable to test whether a given fraction might have a composite nature.

Increasing OM content with decreasing particle size may be explained by (i) a lower efficiency of ultrasonic dispersion to detach OM patches from small clay particles than from larger silt particles as suggested by Chenu and Plante (2006), (ii) the accumulation of colloidal OM released by the previous dispersion of coarser aggregates or (iii) may result from variations in settling velocities as a result of small variations in density. The unavoidable violation of the conditions for the application of Stokes' law (spherical shape, uniform density) will have introduced an error and will have enhanced the organic content of fine fractions, as the speed of sedimentation of light organic-rich particles is slower than the one of heavy mineral grains, for a given diameter (see also Fig. 5 step 2). Although the fraction $<0.035 \mu \mathrm{m}$ (P16) was relatively depleted in mineral matter, its carbon content suggested that it might not have been completely mineral free. Therefore P16, while probably containing much of the carbon that was previously in dissolved form, can not be considered a robust proxy for dissolved organic matter (DOM).

\section{2 ${ }^{15} \mathrm{~N}$ tracer distribution and evaluation of the turnover of processes captured by physical fractions}

Coarse light PSDF fractions from P1 to P4 displayed contrasting levels of ${ }^{15} \mathrm{~N}$ excess or relative enrichment of the 
${ }^{15} \mathrm{~N}$ label over total $\mathrm{N}$ in the fraction. As they plotted on the pole of pure OM, they keyed out as a functionally homogeneous group that are especially relevant for the representation of processes directly related to decomposer activity; they can also be considered as controlling $\mathrm{N}$ cycling, with little influence from the mineral phases. The maximum of ${ }^{15} \mathrm{~N}$ excess was associated with the $630-200 \mu \mathrm{m}$ fraction (P3) at Fougères, and with the 200-63 $\mu \mathrm{m}$ fraction (P4) at Ebrach. This indicates that faunal fragmentation and microbial transformation of the labelled litter was more advanced at Ebrach than at Fougères, which was not necessarily expected.

Contrastingly, mineral-rich fractions represented by the coarse dense PSDF fractions and the ADF fractions above $1.85 \mathrm{~g} \mathrm{~cm}^{-3}$ incorporated very little tracer- $\mathrm{N}$ a decade after its application. This shows that they represent reservoirs of older organic $\mathrm{N}$ in forest soil. They either cycled nitrogen very slowly, or came only seldom into contact with the label during the decade since application, most likely because the label was preferentially retained in the OM rich fractions. Still, a distinction must be made between the mineral-rich fractions isolated either by size or density regarding their relevance to $\mathrm{N}$ cycling processes. Coarse dense PSDF fractions consisting of individual grains coated with adsorbed $\mathrm{OM}$ exhibited no real difference in terms of ${ }^{15} \mathrm{~N}$ tracer incorporation. This might either be a consequence of the fact that size separation of coarse dense fractions was not able to separate defined mineralogical fractions that would have influenced nitrogen dynamics, or due to a level of tracer close to the detection limit of the instrument. More interestingly, the (low) level of tracer in ADF fractions progressively decreased as density increased. These fractions thus appear to be particularly promising as tools for the investigation of time-dependent $\mathrm{N}$ sequestration mechanisms (see Hatton et al., 2012 for example).

We suggest that the operational nature of the dispersion and separation procedure may be responsible for the observation that the enrichment of ${ }^{15} \mathrm{~N}$ tracer was relatively homogeneous within the finest fractions isolated by PSDF, while the ${ }^{15} \mathrm{~N}$ mass flow was very variable. This adds to the methodological artefacts already revealed by the location of the fraction in the PCA plane and emphasizes the observation that fine particle size fractions can not be treated as functional soil compartments regarding $\mathrm{N}$ and $\mathrm{OM}$ cycling. They constitute a heterogeneous mixture of debris and leftovers of both mineral and organic components and can not be expected to exist as a physical reality in natural soil.

\subsection{Identification of functional soil compartments (FSC's) among physical fractions}

Our observations on OM characteristics and $\mathrm{N}$ cycling can be synthesized to identify functional soil compartments (FSC). Functional soil compartments are defined as groups of fractions which exist as a physical reality in soil and which are distinguished by fundamentally different process regimes controlling organic matter transformation and decomposition processes (Table 1 and 5). We identified three groups of functional soil compartments. They are listed below and in Figs. 4 and 5 .

1. Free particulate organic matter (POM), where litterderived $\mathrm{N}$ resides for about one decade in the forest ecosystems examined (A1, P1-6);

2. Non-aggregated mineral particles with adsorbed organic matter, location of $\mathrm{N}$ cycling processes occurring on a timescale longer than decades (A6-A7, P7-P12);

3. Aggregates, also determining $\mathrm{N}$ dynamics on pluridecadal timescales in soil (A2-A5);

4. Although it is often implicitly assumed that ultrasonically dispersed fine fractions represent an FSC associated with adsorbed OM (e.g. Six et al., 2002a), their composite nature (i.e. undefined mixture of mineral particles, aggregates and free $\mathrm{OM}$ ), prevents them from being considered as true functional compartments.

\subsection{PSDF versus ADF procedures: recommendations}

Both ADF and PSDF successfully isolated the functional soil compartment "POM" as well as non-aggregated mineral particles coated with OM. To support an eventual decision in favour of any of the two methods, we offer the following recommendations. PDSF is better suited than ADF to investigate the dynamics of POM, as POM sizes are a direct function of the natural fragmentation that occurs with the decomposition process. In the case of mineral particles associated with adsorbed carbon, ADF isolated fewer of these fractions (i.e. A6 and A7) than PSDF (i.e. P7-P12). Yet, since the mineralogy and the resulting adsorption capacity of a particle are more directly linked to its density than to its size, the ADF must be considered to be more appropriate for the investigation of the dynamics of adsorbed OM than the PSDF. Finally, only $\mathrm{ADF}$ isolates true aggregates.

We conclude that the two fractionation methods can not be considered alternatives; they should rather be seen as complementary. We also recognize 4 major methodological issues of the PSDF procedure which need to be considered when data are interpreted:

1. Density separation in water as performed in PSDF is not designed to achieve strict separation of the mineral and organic phases and therefore generates impurities. Coarse dense and coarse light fractions were slightly contaminated with residual POM and black carbon in one case, as well as mineral grains in the other case. The contamination issue is negligible for coarse light fractions (see also Fig. 7 steps 3 and 8).

2. Ultrasonic dispersion at the energy level chosen for this work (i.e. $320 \mathrm{~J} \mathrm{ml}^{-1}$, delivered over a $20 \mathrm{~min}$ period 
Table 5. Identification of functional soil compartment (FSC) among physical fractions.

\begin{tabular}{|c|c|c|c|c|}
\hline Soil subunit & $\begin{array}{l}\text { Represented } \\
\text { by }\end{array}$ & FSC? & $\begin{array}{l}\text { Associated processes } \\
\text { and their timescale }\end{array}$ & Remarks \\
\hline $\begin{array}{l}\text { Particulate organic } \\
\text { matter (POM) }\end{array}$ & $\begin{array}{l}\text { PSDF: (P1 to P6) } \\
\text { and ADF: (A1) }\end{array}$ & Yes & $\begin{array}{l}\text { Progressive processing by mesofauna, } \\
\text { provides adhesive nuclei for aggregate } \\
\text { formation } \\
\text { Year to decade }\end{array}$ & $\begin{array}{l}\text { POM fractions isolated by PSDF represent } \\
\text { a decomposition gradient that can be seen } \\
\text { as representing the litter-soil organic matter } \\
\text { transition. ADF with only one fraction can } \\
\text { not characterize the dynamics in this cohort. } \\
\text { Changes in this fraction are independent from } \\
\text { interactions with minerals. }\end{array}$ \\
\hline Aggregated stuctures & ADF: (A2 to A5) & Yes & $\begin{array}{l}\text { Physical isolation of substrate from } \\
\text { decomposition actors and factors } \\
\text { (i.e. microbes, } \mathrm{O}_{2} \text { and } \mathrm{H}_{2} \mathrm{O} \text { supply, etc.) } \\
\text { within defined micro-environments } \\
\text { Several decades }\end{array}$ & $\begin{array}{l}\text { ADF is effective at isolating functional micro- } \\
\text { structures. The biogeochemical stability of } \\
\text { individual aggregates, the proportion of mineral } \\
\text { materials and the microbial characteristics } \\
\text { increase with increasing aggregate density. }\end{array}$ \\
\hline $\begin{array}{l}\text { Coarse mineral grain } \\
\text { coated with OM }\end{array}$ & $\begin{array}{l}\text { PSDF: (P7 to P12) } \\
\text { and } \\
\text { ADF: (A6 to A7) }\end{array}$ & Yes & $\begin{array}{l}\text { All processes that are controlled by } \\
\text { surface chemistry, including adsorption, } \\
\text { electron transfer, catalytic effects. } \\
\text { Involved dissolved organic matter } \\
\text { generated in any stage of decomposition } \\
\text { Several decades }\end{array}$ & $\begin{array}{l}\text { Organic matter associated with the mineral } \\
\text { grains isolated by ADF had a greater microbial } \\
\text { character than such as was isolated by PSDF. }\end{array}$ \\
\hline Residuals & PSDF: (P13 to P16) & No & Does not represent specific soil process & $\begin{array}{l}\text { These fractions represent a mixture of mineral } \\
\text { and organic materials that (1) were incom- } \\
\text { pletely dispersed, that (2) could not be } \\
\text { separated by density in water and that ( } 3 \text { ) } \\
\text { could not be properly separated by size } \\
\text { using the single density assumption of Stokes' } \\
\text { law. These materials were not necessarily } \\
\text { joined or even co-localized in soil. }\end{array}$ \\
\hline
\end{tabular}

$\mathrm{PSDF}=$ Particle size density fractionation, $\mathrm{ADF}=$ Aggregate density fractionation.

of time) does not achieve complete dispersion at submicron scales, and was responsible for slight redistributions in the smaller coarse light fractions (i.e. P5, P6) (see also Fig. 7 step 4).

3. There is an absence of good separation within the fine fractions, which are obviously composed of phases with highly variable density. This fact violates the basic condition of all sedimentation separation methods which follow Stokes' law und assume a unique density for all particles (Stokes' Law) (see also Fig. 7 step 5). For this reason, the carbon contained in ultrasonically dispersed fine particle size fractions should not be assumed to have previously been adsorbed to mineral surfaces.

4. Separating coarse dense fractions by size was not very informative.

In response to these findings, we offer a PSDF fractionation protocol that would reduce the creation of ecologically irrelevant fractions in the two soils we investigated. We recommend separating the mineral from the organic phases directly after the dispersion procedures, prior to size separations by wet sieving and sedimentation. To avoid interference of dense organic phases (some forms of charcoal) we suggest

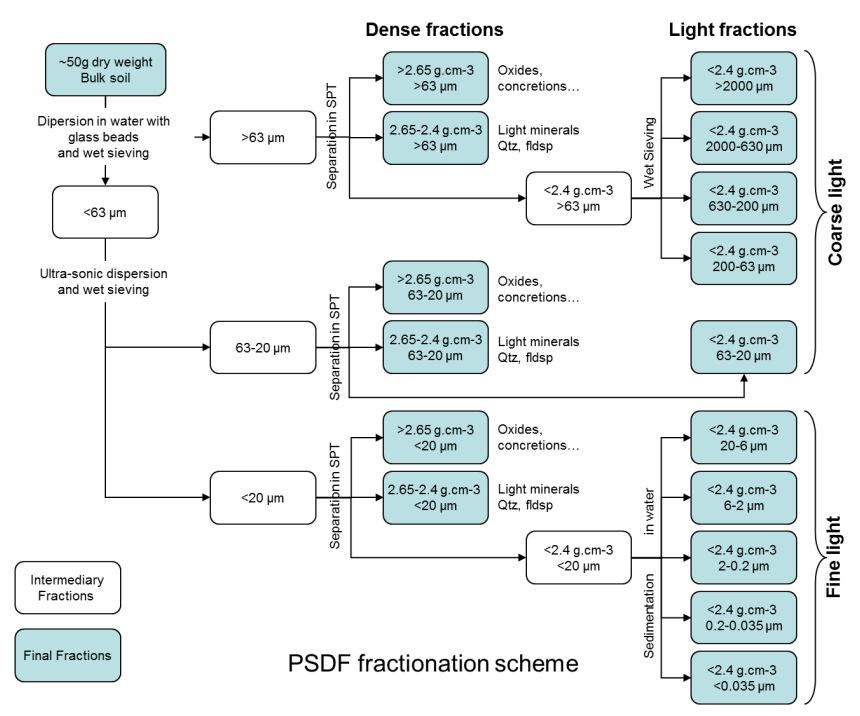

Fig. 8. Suggestion for the improvement of the PSDF fractionation scheme.

adjusting the density of the separating liquid to $2.4 \mathrm{~g} \mathrm{~cm}^{-3}$ (using a solution of sodium polytungstate) to exclude all residual POM, as well as a maximum of black carbon 
particles from the mineral phase. Centrifugation can be used to improve the density separation of fine fractions (Kaiser and Guggenberger, 2007). Finally, we propose abandoning the size separation of the mineral fraction $\left(d>2.4 \mathrm{~g} \mathrm{~cm}^{-3}\right)$. In oxide-rich soils, these fractions could eventually be pooled and further separated by density at $2.65 \mathrm{~g} \mathrm{~cm}^{-3}$ to obtain reactive and less reactive mineral fractions (Fig. 8). Ultrasonication, although unable to achieve complete dispersion at the submicron scale, is still extremely efficient at larger size scales and should be kept for that reason. Finally, the size separation of light fraction $<20 \mu \mathrm{m}$ would be performed after density exclusion of dense fractions to limit the effects of varying particle density during sedimentation. The fine light fraction recovered with this procedure should be a mixture of free POM and aggregates. The proportion of POM will decline with decreasing size. The characteristics of the fractions recovered with this new procedure are displayed in Fig. 5b.

Most contemporary PSDF procedures opt for a separation of the organic phase at $\sim 1.6-1.8 \mathrm{~g} \mathrm{~cm}^{-3}$ after various degrees of dispersion (e.g. Bruun et al., 2008; Cerli et al., 2012; Magid et al., 2010; Paul et al., 2008; Shang and Tiessen, 2000; Sohi et al., 2001). In theory this standard method allows the separation of the organic from the mineral phase in most soils, however if applied in soils that contain substantial amounts of black carbon particles and pedogenic oxides, it will not be possible to isolate confounding effects of charcoal when interpreting the fractionation data.

All these issues are resolved with the proposed fractionation procedure (Fig. 8) while keeping the advantages of the old methods. While we are confident that the new protocol should be widely applicable, extending it to other taxonomic soil types soil will require testing and evaluation, especially concerning the selection of density cut-offs and energy levels of dispersion.

\section{Conclusions}

1. We set out to test whether physical fractionation would allow us to identify functional subunits of the soil fabric, particularly regarding litter-derived $\mathrm{N}$ dynamics. We demonstrated how this can be achieved (Table 5). We further showed that both fractionation procedures yielded complementary information about $\mathrm{N}$ dynamics. PSDF fractionation was more useful for the investigation of the natural fragmentation of POM at a decadal timescale, whereas ADF should be the superior choice for applications investigations of sorptive interactions and aggregation processes at a pluri-decadal timescale. This suggests that litter-derived $\mathrm{N}$ dynamics, and by extension, SOM dynamics, can not be fully understood when the fractionation protocol is restricted to a unique single step fractionation procedure.

2. We noted some shortcomings of the PSDF procedure, the most important one being that fine fractions isolated after sonication can not be linked to any defined decomposition pathway or stabilisation process. An improved PSDF fractionation procedure was proposed to address most of the methodological issues observed in the studied soils.

3. Our work demonstrated that it is fundamentally possible to use physical fractionation for the purpose of isolating organic matter of progressing decomposition stage from soils. This applies to organic matter associated with minerals as well as to particulate organic matter. Figure 8 illustrates how this purpose can be achieved through the application of an optimised, combined fractionation scheme.

Acknowledgements. This work was financially supported by the Department of Crop and Soil Science, Oregon State University start-up funds to M. K. and by the Institut National de la Recherche Agronomique (INRA-EFPA) and the Région Lorraine (Grant 12000162A). The authors are grateful to Rocky Yarwood of the OSU/CSS Stable Isotope Research Unit (SIRU) who performed stable isotope analyses and to Jade Salleles and Isabelle BasileDoelsch who kindly agreed to give constructive comments on earlier versions of the manuscripts.

Edited by: E. Veldkamp

\section{References}

Amelung, W., Bol, R., and Friedrich, C.: Natural C-13 abundance: A tool to trace the incorporation of dung-derived carbon into soil particle-size fractions. Rapid Commun. Mass. Sp., 13, 12911294, 1999.

Arnarson, T. S. and Keil, R. G.: Organic-mineral interactions in marine sediments studied using density fractionation and X-ray photoelectron spectroscopy. Org. Geochem., 32, 1401-1415, 2001.

Baisden, W. T., Amundson, R., Cook, A. C., and Brenner, D. L.: Turnover and storage of $\mathrm{C}$ and $\mathrm{N}$ in five density fractions from California annual grassland surface soils, Global Biogeochem. Cy., 16, 1117, doi:10.1029/2001GB001822, 2002.

Balabane, M. and Plante, A. F.: Aggregation and carbon storage in silty soil using physical fractionation techniques, Eur. J. Soil Sci., 55, 415-427, 2004.

Balesdent, J.: The significance of organic separates to carbon dynamics and its modelling in some cultivated soils, Eur. J. Soil Sci., 47, 485-493, 1996.

Balesdent, J., Petraud, J.-P., and Feller, C.: Effets des ultrasons sur la distribution granulometrique des maitres organiques des sols, Science du Sol, 29, 95-106, 1991.

Balesdent, J., Besnard, E., Arrouays, D., and Chenu, C.: The dynamics of carbon in particle-size fractions of soil in a forestcultivation sequence, Plant Soil, 201, 49-57, 1998.

Basile-Doelsch, I., Amundson, R., Stone, W. E. E., Borschneck, D., Bottero, J. Y., Moustier, S., Masin, F., and Colin, F.: Mineral control of carbon pools in a volcanic soil horizon, Geoderma, 137, 477-489, 2007. 
Basile-Doelsch, I., Brun, T., Borschneck, D., Masion, A., Marol, C., and Balesdent, J.: Effect of landuse on organic matter stabilized in organomineral complexes: A study combining density fractionation, mineralogy and delta(13)C, Geoderma, 151, 7786, 2009.

Bayer, C., Martin-Neto, L., Mielniczuk, J., and Ceretta, C. A.: Effect of no-till cropping systems on soil organic matter in a sandy clay loam Acrisol from Southern Brazil monitored by electron spin resonance and nuclear magnetic resonance, Soil Till. Res., 53, 95-104, 2000.

Billings, S. A.: Soil organic matter dynamics and land use change at a grassland/forest ecotone. Soil Biol. Biochem., 38, 2934-2943, 2006.

Bock, M. J. and Mayer, L. M.: Mesodensity organo-clay associations in a near-shore sediment, Mar. Geol., 163, 65-75, 2000.

Bruun, S., Thomsen, I. K., Christensen, B. T., and Jensen, L. S.: In search of stable soil organic carbon fractions: a comparison of methods applied to soils labelled with C-14 for 40 days or 40 years, Eur. J. Soil Sci., 59, 247-256, 2008.

Castanha, C., Trumbore, S., and Amundson, R.: Methods of separating soil carbon pools affect the chemistry and turnover time of isolated fractions, Radiocarbon, 50, 83-97, 2008.

Cayet, C. and Lichtfouse, E.: delta C-13 of plant-derived n-alkanes in soil particle-size fractions, Org. Geochem., 32, 253-258, 2001.

Cerli, C., Celi, L., Kalbitz, K., Guggenberger, G., and Kaiser, K.: Separation of light and heavy organic matter fractions in soil - Testing for proper density cut-off and dispersion level, Geoderma, 170, 403-416, 2012.

Chenu, C. and Plante, A. F.: Clay-sized organo-mineral complexes in a cultivation chronosequence: revisiting the concept of the "primary organo-mineral complex", Eur. J. Soil Sci., 57, 596607, 2006

Crow, S. E., Swanston, C. W., Lajtha, K., Brooks, J. R., and Keirstead, H.: Density fractionation of forest soils: methodological questions and interpretation of incubation results and turnover time in an ecosystem context, Biogeochemistry, 85, 6990, 2007.

Derrien, D., Marol, C., Balabane, M., and Balesdent, J.: The turnoverof carbohydrate carbon in a cultivated soil estimated by ${ }^{13} \mathrm{C}$ natural abundances, Eur. J. Soil Sci., 57, 547-557, 2006.

Echeverria, M. E., Markewitz, D., Morris, L. A., and Hendrick, R. L.: Soil organic matter fractions under managed pine plantations of the southeastern USA, Soil Sci. Soc. Am. J., 68, 950-958, 2004.

IUSS Working Group: World Reference Base for Soil Resources 2006, World Soil Resources Reports No 103, 2nd Edn., FAO, Rome, 2006.

Glaser, B., Balashov, E., Haumaier, L., Guggenberger, G., and Zech, W.: Black carbon in density fractions of anthropogenic soils of the Brazilian Amazon region, Org. Geochem., 31, 669-678, 2000.

Golchin, A., Oades, J. M., Skjemstad, J. O., and Clarke, P.: Study of free and occluded particulate organic matter in soils by solid state ${ }^{13} \mathrm{C}$ CP/MAS NMR Spectroscopy and Scanning Electron Microscopy, Aust. J. Soil Res., 32, 285-309, 1994a.

Golchin, A., Oades, J. M., Skjemstad, J. O., and Clarke, P.: SoilStructure and Carbon Cycling, Aust. J. Soil Res., 32, 1043-1068, 1994b.
Golchin, A., Clarke, P., Oades, J. M., and Skjemstad, J. O.: The Effects of Cultivation on the Composition of Organic-Matter and Structural Stability of Soils, Aust. J. Soil Res., 33, 975-993, 1995a.

Golchin, A., Oades, J. M., Skjemstad, J. O., and Clarke, P.: Structural and Dynamic Properties of Soil Organic-Matter as Reflected by ${ }^{13} \mathrm{C}$ Natural-Abundance, Pyrolysis MassSpectrometry and Solid-State ${ }^{13} \mathrm{C}$ Nmr-Spectroscopy in Density Fractions of an Oxisol under Forest and Pasture, Aust. J. Soil Res., 33, 59-76, 1995b.

Gregorich, E. G., Beare, M. H., Mckim, U. F., and Skjemstad, J. O.: Chemical and biological characteristics of physically uncomplexed organic matter, Soil Sci. Soc. Am. J., 70, 975-985, 2006.

Hatton, P.-J., Kleber, M., Zeller, B., Moni, C., Plante, A. F., Townsend, K., Gelhaye, L., Lajtha, K., and Derrien, D. Transfer of litter-derived $\mathrm{N}$ to soil mineral-organic associations: Evidence from decadal ${ }^{15} \mathrm{~N}$ tracer experiments. Org. Geochem., 42, 1489-1501, 2012.

Huygens, D., Boeckx, P., Van Cleemput, O., Oyarzún, C., and Godoy, R.: Aggregate and soil organic carbon dynamics in South Chilean Andisols, Biogeosciences, 2, 159-174, doi:10.5194/bg2-159-2005, 2005.

Jimenez, J. J., Lorenz, K., and Lal, R.: Organic carbon and nitrogen in soil particle-size aggregates under dry tropical forests from Guanacaste, Costa Rica - Implications for within-site soil organic carbon stabilization, Catena, 86, 178-191, 2011.

John, B., Flessa, H., Yamashita, T., and Ludwig, B.: Storage of organic carbon in aggregate and density fractions of silty soils under different types of land use, Geoderma, 128, 63-79, 2005.

Kaiser, K. and Guggenberger, G.: Distribution of hydrous aluminium and iron compounds over density fractions depends on organic matter load and ultrasonic dispersion, Geoderma, 140, 140-146, 2007.

Kapkiyai, J. J., Woomer, P. L., Karanja, N. K., Qureshi, J. N., and Smithson, P. C.: Soil organic matter and nutrient dynamics in a Kenyan nitisol under long-term fertilizer and organic input management, Soil Biol. Biochem., 31, 1773-1782, 1999.

Kong, A. Y. Y., Six, J., Bryant, D. C., Denison, R. F., and van Kessel, C.: The relationship between carbon input, aggregation, and soil organic carbon stabilization in sustainable cropping systems, Soil Sci. Soc. Am. J., 69, 1078-1085, 2005.

Lehmann, J., Cravo, M. D., and Zech, W.: Organic matter stabilization in a Xanthic Ferralsol of the central Amazon as affected by single trees: chemical characterization of density, aggregate, and particle size fractions, Geoderma, 99, 147-168, 2001.

Magid, J., De Nowina, K. R., Lindedam, J., and Andren, O.: Organic matter in size-density fractions after 16-50 years of grass ley, cereal cropping and organic amendments, Eur. J. Soil Sci., 61, 539-550, 2010.

Moni, C., Chenu, C., Rumpel, C., Virto, I., and Chabbi, A.: Relative importance of sorption versus aggregation for organic matter storage in subsoil horizons of two contrasting soils, Eur. J. Soil Sci., 61, 958-969, 2010.

Morra, M. J., Blank, R. R., Freeborn, L. L., and Shafii, B.: Size Fractionation of Soil Organo-Mineral Complexes Using Ultrasonic Dispersion, Soil Sci., 152, 294-303, 1991.

Nelson, P. N., Dictor, M. C., and Soulas, G.: Availability of OrganicCarbon in Soluble and Particle-Size Fractions from a SoilProfile, Soil Biol. Biochem., 26, 1549-1555, 1994. 
Oades, J. M.: Soil Organic-Matter and Structural Stability - Mechanisms and Implications for Management, Plant Soil, 76, 319337, 1984.

Oades, J. M. and Waters, A. G.: Aggregate Hierarchy in Soils, Aust. J. Soil Res., 29, 815-828, 1991.

Oorts, K., Vanlauwe, B., Recous, S., and Merckx, R.: Redistribution of particulate organic matter during ultrasonic dispersion of highly weathered soils, Eur. J. Soil Sci., 56, 77-91, 2005.

Paul, S., Veldkamp, E., and Flessa, H.: Soil organic carbon in density fractions of tropical soils under forest - pasture - secondary forest land use changes, Eur. J. Soil Sci., 59, 359-371, 2008.

Poppe, L. J., Fredericks, J. J., and Hathaway, J. C.: A ComputerProgram to Calculate Centrifugation Parameters for Sedimentation Analyses, Comput. Geosci., 14, 541-545, 1988.

Ranjard, L., Nazaret, S., Poly, F., Combrisson, J., Richaume, A., Gourbiere, F., and Thioulouse, J.: Heterogeneous cell density and genetic structure of bacterial pools associated with various soil microenvironments as determined by enumeration and DNA fingerprinting approach (RISA), Microb. Ecol., 39, 263-272, 2000.

Römkens, P. F. A. M., van der Plicht, J., and Hassink, J.: Soil organic matter dynamics after the conversion of arable land to pasture, Biol. Fert. Soils 28, 277-284, 1999.

Roscoe, R., Buurman, P., and Velthorst, E. J.: Disruption of soil aggregates by varied amounts of ultrasonic energy in fractionation of organic matter of a clay Latosol: carbon, nitrogen and delta ${ }^{13} \mathrm{C}$ distribution in particle-size fractions, Eur. J. Soil Sci., 51, 445-454, 2000.

Rumpel, C., Kogel-Knabner, I., Knicker, H., and Huttl, R. F.: Composition and distribution of organic matter in physical fractions of a rehabilitated mine soil rich in lignite-derived carbon, Geoderma, 98, 177-192, 2000.

Sa, J. C. D., Dick, W. A., Cerri, C. C., Lal, R., Venske, S. P., Piccolo, M. C., and Feigl, B. E.: Organic matter dynamics and carbon sequestration rates for a tillage chronosequence in a Brazilian Oxisol, Soil Sci. Soc. Am. J., 65, 1486-1499, 2001.

Schmidt, M. W. I., Kogel-Knabner, I., and Rumpel, C.: Evaluation of an ultrasonic dispersion procedure to isolate primary organomineral complexes from soils, Eur. J. Soil Sci., 50, 8794, 1999a.

Schmidt, M. W. I., Rumpel, C., and Kogel-Knabner, I.: Particle size fractionation of soil containing coal and combusted particles, Eur. J. Soil Sci., 50, 515-522, 1999b.

Schmidt, M. W. I. and Kögel-Knabner, I.: Organic matter in particle-size fractions from A and B horizons of a Haplic Alisol, Eur. J. Soil Sci., 53, 383-391, 2002.

Schmidt, M. W. I., Knicker, H., and Kogel-Knabner, I.: Organic matter accumulating in Aeh and Bh horizons of a Podzol chemical characterization in primary organo-mineral associations, Org. Geochem., 31, 727-734, 2000.

Schöning, I. and Kögel-Knabner, I.: Chemical composition of young and old carbon pools throughout Cambisol and Luvisol profiles under forests, Soil Biol. Biochem., 38, 2411-2424, 2006.

Shang, C. and Tiessen, H.: Carbon turnover and carbon-13 natural abundance in organo-mineral fractions of a tropical dry forest soil under cultivation, Soil Sci. Soc. Am. J., 64, 2149-2155, 2000.

Shaw, P. J. A.: Multivariate statistics for the environmental sciences, Arnold, Distributed in the United States by Oxford University Press, London, New York, ix, 233 pp., 2003.
Six, J., Elliott, E. T., Paustian, K., and Doran, J. W.: Aggregation and soil organic matter accumulation in cultivated and native grassland soils, Soil Sci. Soc. Am. J., 62, 1367-1377, 1998.

Six, J., Schutz, P. A., Jastrow, J. D., and Merckx, R.: Recycling of sodium polytungstate used in soil organic matter studies, Soil Biol. Biochem., 31, 1193-1196, 1999.

Six, J., Elliott, E. T., and Paustian, K.: Soil macroaggregate turnover and microaggregate formation: a mechanism for $\mathrm{C}$ sequestration under no-tillage agriculture, Soil Biol. Biochem., 32, 2099-2103, 2000.

Six, J., Conant, R. T., Paul E. A., and Paustian, K.: Stabilization mechanisms of soil organic matter: Implications for C-saturation of soils, Plant Soil., 241, 155-176, 2002a.

Six, J., Callewaert, P., Lenders, S., De Gryze, S., Morris, S. J., Gregorich, E. G., Paul, E. A., and Paustian, K: Measuring and Understanding Carbon Storage in Afforested Soils by Physical Fractionation, Soil Sci. Soc. Am. J., 66, 1981-1987, 2002 b.

Sohi, S. P., Mahieu, N., Arah, J. R. M., Powlson, D. S., Madari, B., and Gaunt, J. L.: A procedure for isolating soil organic matter fractions suitable for modeling, Soil Sci. Soc. Am. J., 65, 11211128, 2001.

Sollins, P., Swanston, C., Kleber, M., Filley, T., Kramer, M., Crow, S., Caldwell, B. A., Lajtha, K., and Bowden, R.: Organic C and $\mathrm{N}$ stabilization in a forest soil: Evidence from sequential density fractionation, Soil Biol. Biochem., 38, 3313-3324, 2006.

Solomon, D., Lehmann, J., and Zech, W.:Land use effects on soil organic matter properties of chromic luvisols in semi-arid northern Tanzania: carbon, nitrogen, lignin and carbohydrates, Agr. Ecosyt. Environ., 78, 203-213, 2000.

Solomon, D., Fritzsche, F., Lehmann, J., Tekalign, M., and Zech, W.: Soil organic matter dynamics in the subhumid agroecosystems of the Ethiopian highlands: Evidence from natural ${ }^{13} \mathrm{C}$ abundance and particle-size fractionation, Soil Sci. Soc. Am. J., 66, 969-978, 2002.

Swanston, C. W., Caldwell, B. A., Homann, P. S., Ganio, L., and Sollins, P.: Carbon dynamics during a long-term incubation of separate and recombined density fractions from seven forest soils, Soil Biol. Biochem., 34, 1121-1130, 2002.

Swanston, C. W., Torn, M. S., Hanson, P. J., Southon, J. R., Garten, C. T., Hanlon, E. M., and Ganio, L.: Initial characterization of processes of soil carbon stabilization using forest stand-level radiocarbon enrichment, Geoderma, 128, 52-62, 2005.

Tan, Z., Lal, R., Owens, L., and Izaurralde, R. C.: Distribution of light and heavy fractions of soil organic carbon as related to land use and tillage practice, Soil Till. Res., 92, 53-59, 2007.

Tisdall, J. M. and Oades, J. M.: Organic-Matter and Water-Stable Aggregates in Soils, J. Soil Sci, 33, 141-163, 1982.

Torn, M. S., Swanston, C. W., Castanha, C., and Trumbore, S. E.: Storage and turnover of organic matter in soil, in: BiophysicoChemical Processes Involving Natural Nonliving Organic Matter in Environmental Systems, edited by: Senesi, N., Xing, B., and Huang, P. M., John Wiley \& Sons, Inc, Hoboken, New Jersey, 219-272, 2009.

Virto, I., Barre, P., and Chenu, C.: Microaggregation and organic matter storage at the silt-size scale, Geoderma, 146, 326-335, 2008.

von Lützow, M., Kogel-Knabner, I., Ekschmittb, K., Flessa, H., Guggenberger, G., Matzner, E., and Marschner, B.: SOM fractionation methods: Relevance to functional pools and to stabi- 
lization mechanisms, Soil Biol. Biochem., 39, 2183-2207, 2007.

Whalen, J. K., Bottomley, P. J., and Myrold, D. D.: Carbon and nitrogen mineralization from light- and heavy-fraction additions to soil, Soil Biol. Biochem., 32, 1345-1352, 2000.

Yang, X. M., Drury, C. F., Reynolds, W. D., and MacTavish, D. C.: Use of sonication to determine the size distributions of soil particles and organic matter, Can. J.Soil Sci, 89, 413-419, 2009.
Zeller, B. and Dambrine, E.: Coarse particulate organic matter is the primary source of mineral $\mathrm{N}$ in the topsoil of three beech forests, Soil Biol. Biochem., 43, 542-550, 2011.

Zeller, B., Colin-Belgrand, M., Dambrine, E., and Martin, F.: ${ }^{15} \mathrm{~N}$ partitioning and production of ${ }^{15} \mathrm{~N}$-labelled litter in beech trees following ${ }^{15} \mathrm{~N}$-urea spray, Ann. Sci. Forest., 55, 375-383, 1998.

Zeller, B., Colin-Belgrand, M., Dambrine, E., and Martin, F.: Fate of nitrogen released from ${ }^{15} \mathrm{~N}$-labeled litter in European beech forests, Tree Physiol., 21, 153-162, 2001. 